\title{
Common abnormality of gray matter integrity in substance use disorder and obsessive-compulsive disorder: A comparative voxel-based meta-analysis
}

Benjamin Klugah-Brown ${ }^{\mathrm{a}}$, Chenyang Jianga, Elijah Agoalikuma, Xinqi Zhou ${ }^{\mathrm{a}}$, Liye Zou ${ }^{\mathrm{c}}$, Qian $\mathrm{Yu}^{\mathrm{c}}$, Benjamin Becker ${ }^{\mathrm{a}^{*}}$, Bharat Biswal ${ }^{\mathrm{a}, \mathrm{b}^{*}}$,

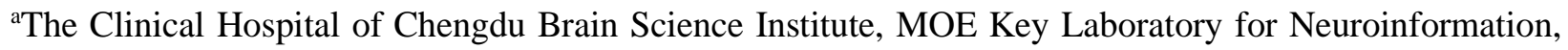
School of Life Science and Technology, University of Electronic Science and Technology of China, No.2006, Xiyuan Avenue, West Hi-Tech Zone, Chengdu, Sichuan 611731, China

${ }^{\mathrm{b}}$ Department of Biomedical Engineering, New Jersey Institute of Technology, 619 Fenster Hall, Newark, NJ 07102, USA

${ }^{\mathrm{c}}$ Exercise \& Mental Health Laboratory, School of Psychology, Shenzhen University, 518060, China

\section{*Corresponding authors}

Bharat Biswal

ORCID ID 0000-0002-3710-3500

Email: bbiswal@gmail.com

Benjamin Becker

ORCID ID 0000-0002-9014-9671

Email: $\underline{\text { ben_becker@gmx.de }}$ 


\begin{abstract}
Aim: To determine robust transdiagnostic brain structural markers for compulsivity by capitalizing on the increasing number of case-control studies examining gray matter alterations in substance use disorders (SUD) and obsessive-compulsive disorder (OCD).

Design: Pre-registered voxel-based meta-analysis of grey matter volume (GMV) changes through seedbased d Mapping (SDM), follow-up functional, and network-level characterization of the identified transdiagnostic regions by means of co-activation and Granger Causality (GCA) analysis.

Participants: Literature search resulted in 31 original VBM studies comparing SUD (n=1191, meanage $=40.03, \mathrm{SD}=10.87)$ and 30 original studies comparing OCD $(\mathrm{n}=1293$, mean-age=29.18, $\mathrm{SD}=10.34)$ patients with healthy controls (SUD: $\mathrm{n}=1585$, mean-age=42.63, SD=14.27, OCD: $\mathrm{n}=1374$, meanage $=28.97, \mathrm{SD}=9.96$ ).

Measurements: Voxel-based meta-analysis within the individual disorders as well as conjunction analysis were employed to reveal common GMV alterations between SUDs and OCD. Meta-analytic coordinates and signed brain volumetric maps determining directed (reduced or increased) brain volumetric alterations between the disorder groups and controls served as the primary outcome. Meta-analytic results employed statistical significance thresholding $(\mathrm{FWE}<0.05)$.

Findings: Separate meta-analysis demonstrated that SUD (cocaine, alcohol, and nicotine) as well as OCD patients exhibited widespread GMV reductions in frontocortical regions including prefrontal, cingulate, and insular regions. Conjunction analysis revealed that the left inferior frontal gyrus (IFG) consistently exhibited decreased GMV across all disorders. Functional characterization suggests that the IFG represents a core hub in the cognitive control network and exhibits bidirectional (Granger) causal interactions with the striatum. Only OCD showed increased GMV in the dorsal striatum with higher changes being associated with more severe OCD symptomatology.
\end{abstract}

Conclusions: Findings demonstrate robustly decreased GMV across the disorders in the left IFG, suggesting a transdiagnostic brain structural marker. The functional characterization as a key hub in the cognitive control network and casual interactions with the striatum suggest that deficits in inhibitory control mechanisms may promote compulsivity and loss of control that characterize both disorders.

Keywords: Compulsivity, substance use disorder, obsessive-compulsive disorder, voxel-based morphometry, coordinate-based meta-analysis 


\section{Introduction}

Obsessive-compulsive disorder (OCD) and substance use disorder (SUD) represent two neuropsychiatric disorders characterized by maladaptive and persistent repetitive behaviors. Typically, OCD involves either hidden or overt ritualistic acts to obtain relief, whereas SUD engages in the consumption of a substance for rewarding effects or relief of distress. Initially, these behaviors serve a specific goal such as relief from emotional, physical, or social distress or rewarding experience. However, during the transition into the pathological state of the disorders, the initial goal-directed behavior becomes progressively habitual and ultimately compulsive. Although compulsivity represents a transdiagnostic key symptom of both disorders and overarching models emphasize the contribution of Pavlovian and instrumental learning mechanism to the development of compulsive behavior in both disorders (Robbins, Gillan, Smith, de Wit, \& Ersche, 2012; Robbins, Vaghi, \& Banca, 2019) the transdiagnostically shared neurobiological mechanisms of the disorders remain to be systematically examined. Also, SUD and OCD often co-occur (Blom et al., 2011; Lochner et al., 2014; Mancebo, Grant, Pinto, Eisen, \& Rasmussen, 2009; Ruscio, Stein, Chiu, \& Kessler, 2010) and co-morbidity has been reported to be a potential source of inefficient treatment (Glazier, Calixte, Rothschild, \& Pinto, 2013).

Accumulating evidence from different lines of research suggests shared brain dysregulations between the disorders, such that both disorders have been characterized by dysregulations in central glutamatergic (Blom et al., 2011; Gass \& Olive, 2008; Pittenger, Bloch, \& Williams, 2011) and dopaminergic signaling which have been associated with key symptoms of both disorders as well as the regulation of behavioral control, associative learning and compulsivity (Bari \& Robbins, 2013; Bellini et al., 2018; Cools, 2008). Moreover, functional neuroimaging studies emphasize an important role of frontocortical circuits in compulsive behavior and accumulating evidence suggests that neurofunctional dysregulations in specific frontocortico-striatal pathways facilitate the development of compulsive symptoms in both disorders (Ó. F. Gonçalves et al., 2016; Milad \& Rauch, 2012; Vollstädt-Klein et al., 2010; Zhou et al., 2019).

Despite evidence from previous meta-analyses suggesting robust brain structural alterations in both, SUD and OCD patients relative to control subjects, shared and separable brain structural alterations between the disorders have not been systematically determined. Previous overarching conceptualizations and neuroimaging studies point to some candidate brain systems that have been identified most consistently, particularly frontostriatal circuits and cortical regions such as the insula (Everitt \& Robbins, 2005; Goldstein et al., 2009; Koob \& Volkow, 2010). Additionally, quantitative and qualitative voxel-base morphometry (VBM) studies have suggested altered gray matter indices in SUDs (see cocaine; (Crunelle et al., 2014; Ide et al., 2014; Rando, Tuit, Hannestad, Guarnaccia, \& Sinha, 2013), Cannabis; (Cousijn et al., 2012; Wetherill et al., 2015), Alcohol; (Xiao et al., 2015; Yang et al., 2016) and Nicotine; (Hanlon et 
al., 2016; Zubieta et al., 2001)) and OCD (Lázaro et al., 2011; Radua, Van Den Heuvel, Surguladze, \& Mataix-Cols, 2010; Rotge et al., 2010; So et al., 2008a) however, the shared gray matter alterations between the disorders have not been determined. Therefore, the determination of shared structural alterations between the disorders may not only facilitate to ascertain the neurostructural basis of compulsivity but may additionally enable the development of clinical interventions, including the determination of promising targets for invasive or non-invasive brain modulation techniques.

Against this background, the present study aimed at determining shared and robust brain structural markers for the disorders by capitalizing on the increasing number of case-control studies examining gray matter alterations in SUD patients and OCD patients relative to healthy control subjects. To this end, we combined original studies from three prevalent substances abused (Alcohol, Cocaine, and Nicotine) which we individually analyzed in a first step. Next, we investigated the shared brain gray matter alterations between SUDs and OCD via voxel-based meta-analysis. This meta-analytic approach has the potential to address the inconsistencies and lack of replicability that often characterizes the original studies on brain structural alterations in psychiatric disorders (Button et al., 2013; Ioannidis, 2011). Based on previous results from functional imaging studies and overarching models of compulsivity we hypothesized that SUDs and OCD will exhibit shared GMV alterations in frontostriatal regions.

Additionally, we aimed to further characterize the identified common region both on the behavioral and network level. To this end, we employed Neurosynth to identify functional co-activation networks of the identified region and employed Granger causality analysis (GCA) to resting-state data from an independent sample of healthy controls to further map the causal relationship between the identified region and the striatum.

\section{Methods}

The present meta-analysis followed the Preferred Reporting Items for Systematic Reviews and MetaAnalyses (PRISMA) (Moher et al., 2014) (shown in Figure 1) and the principles of conducting coordinatebased meta-analysis (Müller et al., 2018). This study has been pre-registered on the OSF repository (Registration DOI: 10.17605/OSF.IO/7YG6J). In the initial step, we identified original studies examining brain structural alteration in SUD (Cocaine, Alcohol, and Nicotine) and OCD by means of MRI-based voxel-based morphometry (VBM). For the literature search, four databases (PubMed, Web of Science, Neurosynth, and Scopus) were utilized and original articles were identified based on relevant references in review studies. Titles and abstracts returned by the search results were examined for subsequent full-text screening and inclusion. Only English language studies reporting whole-brain results in terms of coordinates (3-dimensions (x, y, z) and in Talairach or Montreal Neurological Institute stereotactic space) 
and published between the year 2000 to 2020 were included. The screening process resulted in original peer-reviewed studies employing case-control designs in SUD and OCD, respectively. The following search terms were applied: "Cocaine” OR "Cocaine use disorder" OR “Alcohol” OR "Alcohol use disorder" OR "Nicotine" OR “Smoking” OR “Obsessive-compulsive disorder” AND (Morphometry OR Voxel-based OR voxelwise). Only articles with case-control designs reporting differences between the respective diagnostic group and healthy control subjects were included. Additional exclusion criteria were as follows: (1) articles reporting only region-of-interest (ROI) results, (2) articles with poly-drug users and samples with high comorbidities with psychiatric or somatic disorders (e.g. schizophrenia or HIV), (3) articles focusing on parental drug exposure, and (4) articles reporting results from the same dataset from previous studies, 5 studies including samples lower than $\mathrm{N}=10$ per disorder.

\subsection{Meta-analytic approach}

The meta-analysis of VBM studies was performed using SDM-PSI software version 2.1 (https://www.sdmproject.com/software/). Subsequent functional decoding of the identified regions was conducted via the Neurosynth database (https://neurosynth.org/). The analysis pipeline included the following steps: 1. Extraction of coordinates from peak clusters including their effective sizes (representing the gray matter differences between patients and controls) either in t-value, z-value or p-value (all values in $\mathrm{z}$ and $\mathrm{p}$ were converted to $\mathrm{t}$-value using the statistical converter; https://www.sdmproject.com/utilities/?show=Statistics); 2 . To account for differences between the reported coordinates and the standard space, we created MNI map of the GM for each study using the anisotropic Gaussian kernel with Full-width at half maximum set at $20 \mathrm{~mm}$ and a voxel size of $2 \mathrm{~mm}$; 3 . To account for potential effects of age in each original study mean of the samples was included as a covariate; and 4. Using the effective size maps and the sample sizes of each study variance maps were obtained. We next performed a voxel-wise computation to derive the mean maps by using the weighted mean study maps (obtained using the sample size, variances, and the between-study difference). In the analysis, we first computed the SDM for each disorder, and next a conjunction map was derived by computing the common regions to identify shared brain structural alterations between the four disorders. All meta-analytic results employed statistical significance testing by thresholding the derived maps by voxel-level uncorrected $\mathrm{p}<0.001$ and $\mathrm{FWE}<0.05$ (10 voxels) thresholds.

\subsection{Sensitivity analysis}

We performed whole-brain, voxel-based jackknife sensitivity analysis to determine the robustness of the results by setting a repetition value equal to the number of studies in each sample. The analysis in each of the groups was systematically repeated for $12,9,10$, and 30 times, respectively, while discarding a single study each time. The number of repetitions equals the total number of studies in each sample, i.e. Alcohol 
$(n=12)$, Cocaine $(n=9)$, Nicotine $(n=10)$, and OCD $(n=30)$. This process was repeated until the last study was removed and placed back. The analysis was aimed at determining whether the observed findings are driven by single studies and thus testing the robustness of the group-level results.

2.3 Exploratory analyses of functional characterization: meta-analytic co-activation, causal connectivity and meta-regression

To functionally characterize regions exhibiting shared alterations across the disorders a co-activation analysis of the conjunction results across the diagnostic groups was performed. In the coactivation analysis, we used the inferior frontal gyrus (IFG) ROI co-ordinate to search for networks in the Neurosynth database, the result reflects regions extracted from a large database of previous studies that functionally co-activated with our ROI. Next, based on our apriori hypothesis of the importance of frontostriatal circuits in both disorders and compulsivity, we aimed to investigate causal relationships in the intrinsic interaction between the identified prefrontal (IFG) region and the striatum. Accordingly, resting-state fMRI data from $n=50$ subjects (male; $n=28$, mean age $=21.60$, std=2.01 and female; $n=22$, mean age $=21, \mathrm{std}=2.24$ ) all right-handed were included (for standardized resting-state data preprocessing see (Liu et al., 2019)) to examine the causal interaction of the left IFG with the ipsilateral striatum. We employed GCA (GCA derivation similar to (Benjamin Klugah-Brown et al., 2019)) to investigate the connectivity between the IFG and the targeted areas as it may allow us to explore the interactions between the identified region and the striatum on a causal level. For the technical details of GCA, please refer to the manuscript by Zang and colleagues (Zang, Yan, Dong, Huang, \& Zang, 2012). Based on the meta-analytic determined overlapping GMV alterations between the SUDs and OCD, we defined the IFG as seeds (3mmradius sphere) and striatum (left ventral and dorsal, seeds also known as targets) respectively. The striatal target-seeds were obtained from the human connectome atlas (https://atlas.brainnetome.org/bnatlas.html ) and used $3 \mathrm{~mm}$ radius ROIs for left striatum comprising of the dorsal and ventral striatum, respectively. Furthermore, voxel-wise, residual-based GCA evaluations were made on the mask of the grey matter using the REST toolbox (http://www.restfmri.net). The inflow (from the striatum to IFG), outflow (from IFG to striatum), and out-inflow (net flow) were also computed. The resultant inflow, outflow, and the net flow were further transformed to z-score to improve normality to facilitate the statistical analysis.

To further explore associations with parameters of symptom severity meta-regression analyses were performed. Given that the disorders are characterized by different core symptoms that are assessed via different measures we preformed meta-regression analyses for the duration of substance use for the SUD and Yale-Brown Obsessive Compulsive Scale YBOCs (severity score) for OCD. Note also that the variables are not the same throughout the four disorders, thus, apart from the usual confound (mean age and education), we used duration of substance use for the SUD and YBOCs (severity score) for OCD as 
medRxiv preprint doi: https://doi.org/10.1101/2020.09.03.20187229; this version posted September 3, 2020. The copyright holder for this preprint (which was not certified by peer review) is the author/funder, who has granted medRxiv a license to display the preprint in perpetuity.

It is made available under a CC-BY-NC 4.0 International license .

predictors to examine associations, respectively. Spearman correlation with 95\% confidence levels and thresholded at $\mathrm{p}<0.05$ were employed.

\section{Results}

Literature search performed according to our criteria resulted in a total of 31 original GM VBM studies in SUD $(n=1191$, mean age=40.03, $\mathrm{SD}=10.87)$ and $31 \mathrm{OCD}(\mathrm{n}=1293$, mean age=29.18, $\mathrm{SD}=10.34)$ that compared brain structure via VBM to controls ( SUD: $n=1585$, mean age=42.63, SD=14.27, OCD: $n=1374$, mean age $=28.97, \mathrm{SD}=9.96$ ). The demographic characteristics of the samples from the included studies are presented in Table 1. There are no significant differences among the four groups $(\mathrm{p}<0.05, \mathrm{~F}=8.83)$. The breakdown of the 31 SUD study group comprising of three diagnostic categories is shown in Table 2.

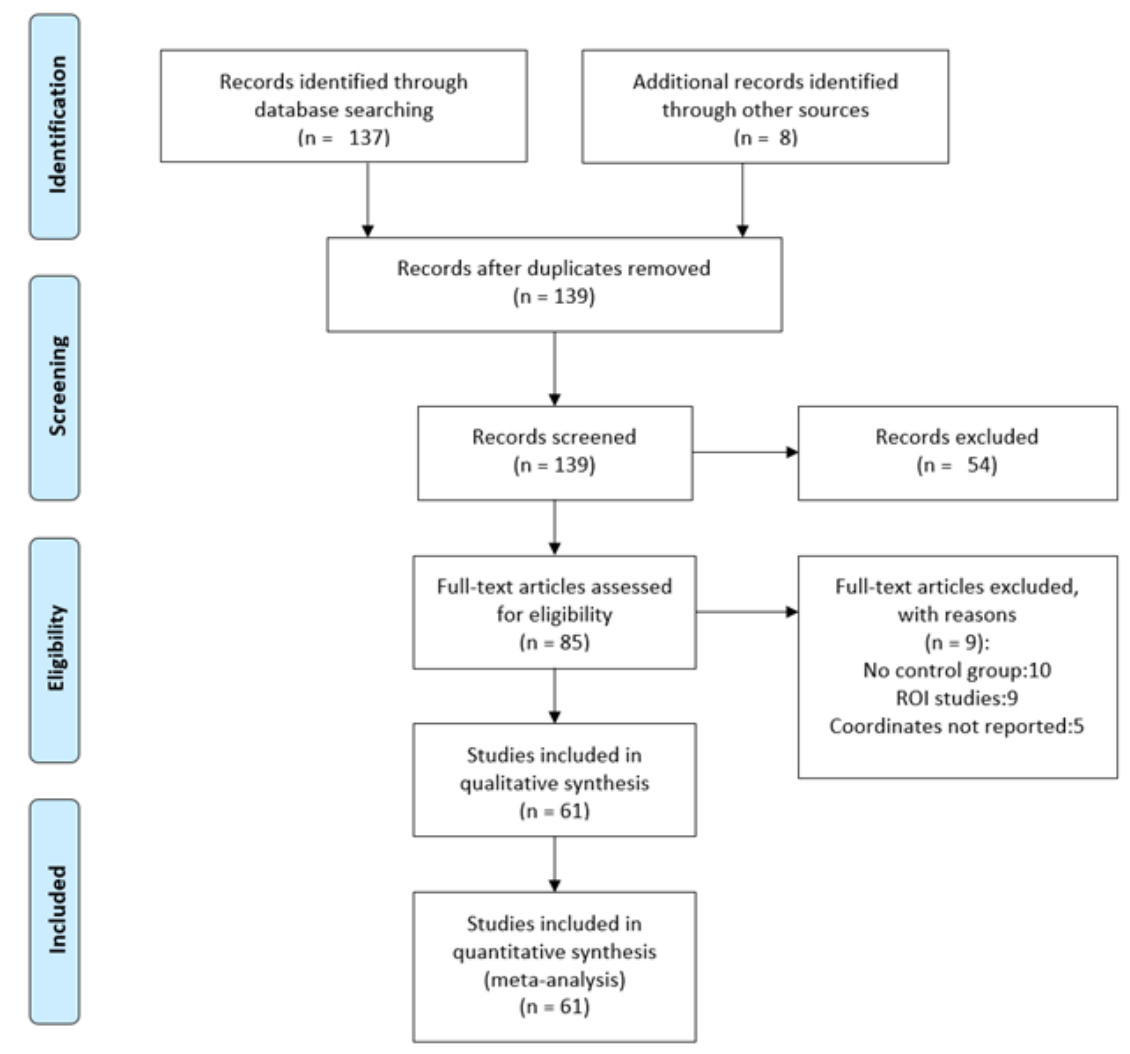

Figure 1 PRISMA. Selection of included studies

Table 1Demography of included studies

\begin{tabular}{|c|c|c|c|c|c|c|c|c|c|c|c|c|}
\hline & n.P & M_ageP & SD & Edu & SD & Duration & SD & n.C & M_ageC & SD & Edu & SD \\
\hline Alcohol & & & & & & & & & & & & \\
\hline $\begin{array}{l}\text { (van Holst, de } \\
\text { Ruiter, van den } \\
\text { Brink, Veltman, }\end{array}$ & 36 & 43.2 & 11.0 & NA & NA & 11.69 & 9.7 & 54 & 35.3 & 10.1 & NA & NA \\
\hline
\end{tabular}




\begin{tabular}{|c|c|c|c|c|c|c|c|c|c|c|c|c|c|}
\hline $\begin{array}{l}\text { \& Goudriaan, } \\
\text { 2012) }\end{array}$ & & & & & & & & & & & & & \\
\hline $\begin{array}{l}\text { (Mechtcheriakov } \\
\text { et al., 2007) }\end{array}$ & 22 & 53.6 & NA & 9.7 & 2.6 & 10 & NA & 22 & 53.7 & NA & 10.1 & 2.3 & \\
\hline $\begin{array}{l}\text { (J. Wang et al., } \\
\text { 2016) }\end{array}$ & 20 & 43.95 & 6.3 & 11.6 & 2.7 & NA & NA & 20 & 40.5 & 8.7 & 9.15 & 4.18 & \\
\hline $\begin{array}{l}\text { (Chanraud et al., } \\
\text { 2007) }\end{array}$ & 26 & 47.7 & 7.1 & 7.58 & 2.96 & NA & NA & 24 & 45 & 6.72 & 8.7 & 3.36 & \\
\hline $\begin{array}{l}\text { (Wiers et al., } \\
\text { 2015) }\end{array}$ & 22 & 42.14 & 6.2 & 10.86 & 1.25 & 14.82 & 7.4 & 21 & 41.95 & 6.41 & 11.62 & 1.62 & \\
\hline $\begin{array}{l}\text { (Galandra et al., } \\
2020)\end{array}$ & 22 & 45.59 & 7.99 & 9.91 & 2.65 & 10.11 & 6.57 & 18 & 44.83 & 8.86 & 10.11 & 2.78 & \\
\hline $\begin{array}{l}\text { (Demirakca et } \\
\text { al., 2011) }\end{array}$ & 50 & 46.6 & 8.2 & NA & NA & 12.4 & 7.4 & 66 & 45 & 10.1 & NA & NA & \\
\hline $\begin{array}{l}\text { (Chanraud et al., } \\
\text { 2009) }\end{array}$ & 24 & 47.8 & 7.7 & 7.75 & 2.99 & NA & NA & 24 & 45 & 5.6 & 8.7 & 3.37 & \\
\hline $\begin{array}{l}\text { (Nurmedov et al., } \\
\text { 2016) }\end{array}$ & 24 & 40.79 & 9.8 & NA & NA & 19 & 9.19 & 29 & 37.45 & $\begin{array}{l}10.8 \\
7\end{array}$ & NA & NA & \\
\hline $\begin{array}{l}\text { (Segobin et al., } \\
\text { 2014) }\end{array}$ & 19 & 44.4 & 6.07 & 11.15 & 1.9 & 29.05 & 7.76 & 20 & 46.7 & 4.25 & 10.6 & 2.58 & \\
\hline $\begin{array}{l}\text { (Galandra et al., } \\
\text { 2018) }\end{array}$ & 23 & 45.69 & 7.82 & 10 & 2.62 & 10.8 & 7.21 & 18 & 44.83 & 8.86 & 10.11 & 2.78 & \\
\hline $\begin{array}{l}\text { (Jang et al., } \\
\text { 2007) }\end{array}$ & 20 & 43.5 & 6 & 14.3 & 4.2 & NA & NA & 20 & 44.5 & 7.4 & 15.3 & 2.6 & \\
\hline \multicolumn{14}{|l|}{ Cocaine } \\
\hline (Sim et al., 2007) & 40 & 41.4 & 6.9 & NA & NA & 15.3 & 6.3 & 41 & 38.7 & 8.8 & NA & NA & \\
\hline $\begin{array}{l}\text { (Vaquero et al., } \\
\text { 2017) }\end{array}$ & 30 & 24 & 6 & NA & NA & NA & NA & 30 & 24 & 6 & NA & NA & \\
\hline $\begin{array}{l}\text { (Franklin et al., } \\
\text { 2002) }\end{array}$ & 13 & 42 & 6.3 & 12 & 1.1 & 13 & 6.5 & 16 & 36.2 & 1 & 17 & 2.6 & \\
\hline (Yip et al., 2018) & 37 & 42.43 & 6.1 & 12.38 & 1.11 & NA & NA & 37 & 38 & $\begin{array}{l}11.0 \\
3\end{array}$ & 14.38 & 1.92 & \\
\hline $\begin{array}{l}\text { (Parvaz et al., } \\
\text { 2017) }\end{array}$ & 19 & 42.58 & 7.63 & 12.68 & 2.75 & 12.74 & 7.42 & 12 & 39.33 & 8.66 & 12.71 & 1.6 & \\
\hline $\begin{array}{l}\text { (Hanlon, Dufault, } \\
\text { Wesley, \& } \\
\text { Porrino, 2011) }\end{array}$ & 24 & 38.9 & 0.9 & NA & NA & 11.1 & 1.2 & 25 & 36.2 & 1 & NA & NA & \\
\hline $\begin{array}{l}\text { (Gardini \& } \\
\text { Venneri, 2012) }\end{array}$ & 14 & 31.07 & 5.86 & 11.21 & 3.33 & 13.41 & 4.94 & 24 & 33.21 & 7.06 & 12.75 & 2.47 & \\
\hline $\begin{array}{l}\text { (Bachi et al., } \\
\text { 2018) }\end{array}$ & 24 & 45.8 & 7.8 & 12.7 & 1.6 & 16.8 & 9.5 & 24 & 41.9 & 7.9 & 14.6 & 1.9 & \\
\hline $\begin{array}{l}\text { (Barrós- } \\
\text { Loscertales et al., } \\
\text { 2011) }\end{array}$ & 20 & 33.3 & 6.94 & 9.2 & 1.7 & NA & NA & 16 & 33.38 & 9.17 & 8.53 & 1.45 & \\
\hline \multicolumn{14}{|l|}{ Nicotine } \\
\hline $\begin{array}{l}\text { (Brody et al., } \\
\text { 2004) }\end{array}$ & 19 & 39.5 & 10.3 & NA & NA & 14.5 & NA & 17 & 37.9 & 12.9 & NA & NA & \\
\hline $\begin{array}{l}\text { (Franklin et al., } \\
\text { 2014) }\end{array}$ & 80 & 33.85 & $\begin{array}{l}10.9 \\
6\end{array}$ & 14.44 & 2.22 & 14.05 & $\begin{array}{l}10.1 \\
3\end{array}$ & 80 & 32.08 & 7.4 & 13.89 & 2.11 & \\
\hline $\begin{array}{l}\text { (Gallinat et al., } \\
\text { 2006) }\end{array}$ & 22 & 30.8 & 7.5 & NA & NA & 13.9 & 7.3 & 23 & 30.3 & 7.9 & NA & NA & \\
\hline $\begin{array}{l}\text { (Hanlon et al., } \\
\text { 2016) }\end{array}$ & 58 & 31.69 & NA & 20.97 & 1.02 & NA & NA & 60 & 29 & NA & 21.53 & 0.88 & \\
\hline $\begin{array}{l}\text { (Liao, Tang, Liu, } \\
\text { Chen, \& Hao, } \\
\text { 2012) }\end{array}$ & 44 & 28.1 & 5.5 & 13.2 & 2.92 & 10.4 & 5.72 & 44 & 26.3 & 5.84 & 15 & 2.6 & \\
\hline $\begin{array}{l}\text { (Morales, Lee, } \\
\text { Hellemann, } \\
\text { O'Neill, \& } \\
\text { London, 2012) }\end{array}$ & 25 & 35.4 & 1.8 & 14.1 & 0.3 & NA & NA & 18 & 30.1 & 2.2 & 14.6 & 0.4 & \\
\hline $\begin{array}{l}\text { (Peng et al., } \\
\text { 2017) }\end{array}$ & 27 & 32.26 & 3.73 & 19.3 & 1.32 & 12.7 & 8.3 & 53 & 30.83 & 5.18 & 19.32 & 1.29 & \\
\hline $\begin{array}{l}\text { (K. Wang et al., } \\
\text { 2014) }\end{array}$ & 22 & 22.48 & 2.48 & 15.14 & 1.83 & 4.95 & 2.27 & 20 & 21.8 & 1.32 & 15.2 & 1.19 & \\
\hline $\begin{array}{l}\text { (Yokoyama et } \\
\text { al., 2018) }\end{array}$ & 50 & 37.73 & 7.9 & NA & NA & NA & NA & 50 & 35.93 & 9.08 & NA & NA & \\
\hline $\begin{array}{l}\text { (Fritz et al., } \\
\text { 2014) }\end{array}$ & 315 & 44.1 & $\begin{array}{l}11.8 \\
4\end{array}$ & NA & NA & 26.8 & 3 & 659 & 51.49 & $\begin{array}{l}14.4 \\
5\end{array}$ & NA & NA & \\
\hline OCD & & & & & & & & & & & & & YBOCS \\
\hline $\begin{array}{l}\text { (Britton et al., } \\
2010)\end{array}$ & 15 & 13.5 & 2.4 & NA & NA & 4.1 & 2 & 20 & 13.6 & 2.4 & NA & NA & 3.34 \\
\hline $\begin{array}{l}\text { (Carmona et al., } \\
\text { 2007) }\end{array}$ & 18 & 13 & 2.76 & NA & NA & NA & NA & 18 & 13.03 & 3.04 & NA & NA & 21.39 \\
\hline $\begin{array}{l}\text { (B. Cheng et al., } \\
\text { 2016) }\end{array}$ & 30 & 10.8 & 2.1 & 4.6 & 2.2 & NA & NA & 30 & 10.5 & 2.2 & 14.4 & 1.8 & 5.21 \\
\hline
\end{tabular}


medRxiv preprint doi: https://doi.org/10.1101/2020.09.03.20187229; this version posted September 3, 2020. The copyright holder for this preprint (which was not certified by peer review) is the author/funder, who has granted medRxiv a license to display the preprint in perpetuity. It is made available under a CC-BY-NC 4.0 International license.

\begin{tabular}{|c|c|c|c|c|c|c|c|c|c|c|c|c|c|}
\hline $\begin{array}{l}\text { (Christian et al., } \\
\text { 2008) }\end{array}$ & 21 & 38 & 9.6 & 27 & 4.2 & NA & NA & 21 & 38.9 & 9.8 & 27 & 4.2 & 27 \\
\hline $\begin{array}{l}\text { (de Wit et al., } \\
\text { 2015) }\end{array}$ & 412 & 32.1 & 9.6 & 13.7 & 2.8 & NA & NA & 368 & 30.2 & 9.3 & 13.7 & 2.8 & 3.35 \\
\hline $\begin{array}{l}\text { (Gilbert, Mataix- } \\
\text { Cols, et al., 2008) }\end{array}$ & 25 & 37.5 & 10.7 & NA & NA & NA & NA & 20 & 29.8 & 7.86 & NA & NA & 26.9 \\
\hline $\begin{array}{l}\text { (Gilbert, } \\
\text { Keshavan, et al., } \\
2008 \text { ) }\end{array}$ & 10 & 12.9 & 2.7 & NA & NA & NA & NA & 10 & 13.4 & 2.6 & NA & NA & 26.5 \\
\hline $\begin{array}{l}\text { (O. F. Gonçalves } \\
\text { et al., 2017) }\end{array}$ & 15 & 31.67 & $\begin{array}{l}11.4 \\
4\end{array}$ & 13 & 3.55 & NA & NA & 15 & 30.07 & 8.22 & 13 & 3.55 & 4.14 \\
\hline $\begin{array}{l}\text { (Hashimoto et } \\
\text { al., 2014) }\end{array}$ & 15 & 32.5 & 7.7 & 13.6 & 1.8 & 5.2 & 2.5 & 30 & 32.5 & 6.7 & 13.6 & 1.8 & 5.61 \\
\hline $\begin{array}{l}\text { (Van Den Heuvel } \\
\text { et al., 2009) }\end{array}$ & 55 & 33.7 & 9.19 & NA & & NA & & 50 & 31.4 & 7.64 & NA & NA & 22.83 \\
\hline $\begin{array}{l}\text { (Kim et al., } \\
\text { 2001) }\end{array}$ & 25 & 27.4 & 7 & 8.4 & & 8.4 & & 25 & 27 & 6.2 & 15.3 & NA & 24.2 \\
\hline $\begin{array}{l}\text { (Kobayashi et al., } \\
\text { 2015) }\end{array}$ & 20 & 31.1 & 8.5 & NA & NA & 11.5 & 7.5 & 30 & 31.2 & 8.5 & NA & NA & 2.46 \\
\hline $\begin{array}{l}\text { (Kopřivová et al., } \\
\text { 2009) }\end{array}$ & 14 & 28.6 & 6.1 & NA & NA & 15.6 & 8.3 & 15 & 28.7 & 6.5 & NA & NA & 5.92 \\
\hline $\begin{array}{l}\text { (Matsumoto et } \\
\text { al., 2010) }\end{array}$ & 16 & 32.8 & 7.5 & NA & NA & NA & NA & 32 & 32.6 & 8.7 & NA & NA & 3.37 \\
\hline $\begin{array}{l}\text { (Moon \& Jeong, } \\
2018 \text { ) }\end{array}$ & 18 & 27.6 & 8 & 14.4 & 1.8 & 6.5 & 5.3 & 18 & 30.7 & 7.5 & 14.4 & 1.8 & 3.71 \\
\hline $\begin{array}{l}\text { (Moreira et al., } \\
\text { 2017) }\end{array}$ & 40 & 26.28 & 6.62 & 13.53 & 2.25 & NA & NA & 40 & 26.45 & 5.39 & 13.53 & 2.25 & 3.36 \\
\hline $\begin{array}{l}\text { (Okada et al., } \\
\text { 2015) }\end{array}$ & 37 & 34.4 & 10.5 & 13.8 & 2.1 & 8.8 & 6.2 & 37 & 36.8 & 10.8 & 13.8 & 2.1 & 2.52 \\
\hline $\begin{array}{l}\text { (Pujol et al., } \\
\text { 2004) }\end{array}$ & 72 & 29.8 & 10.5 & 13 & & 13 & & 72 & 30.1 & 10.2 & 14 & NA & 26.7 \\
\hline (So et al., 2008b) & 71 & 26.61 & 7.5 & NA & NA & 8.02 & 6.1 & 71 & 26.68 & 6.09 & NA & NA & 3.89 \\
\hline $\begin{array}{l}\text { (Soriano-Mas et } \\
\text { al., 2007) }\end{array}$ & 30 & 29.8 & 10.5 & 11.3 & & 11.3 & & 30 & 30.1 & 10.2 & 13.1 & NA & 21 \\
\hline $\begin{array}{l}\text { (Subirà et al., } \\
\text { 2013) }\end{array}$ & 30 & 32.23 & 9.05 & NA & NA & NA & NA & 95 & 33.92 & $\begin{array}{l}10.5 \\
3\end{array}$ & NA & NA & 4.45 \\
\hline $\begin{array}{l}\text { (Subirà et al., } \\
\text { 2015) }\end{array}$ & 71 & 32.11 & 8.45 & NA & NA & NA & NA & 87 & 32.13 & 9.57 & NA & NA & 4.12 \\
\hline $\begin{array}{l}\text { (Szeszko et al., } \\
2008)\end{array}$ & 37 & 13 & 2.7 & NA & NA & NA & NA & 26 & 13 & 2.6 & NA & NA & 24.9 \\
\hline (Tan et al., 2013) & 28 & 25.35 & 7.24 & 13.73 & 2.99 & NA & NA & 22 & 27.88 & 8.02 & 13.73 & 2.99 & 4.14 \\
\hline $\begin{array}{l}\text { (Wanjie Tang et } \\
\text { al., 2013) }\end{array}$ & 18 & 25.5 & 6.7 & NA & NA & 11.1 & 3.9 & 26 & 25.2 & 6.6 & NA & NA & 4.48 \\
\hline $\begin{array}{l}\text { (Wanjie Tang et } \\
\text { al., 2015) }\end{array}$ & 26 & 25.5 & 4.9 & 14.1 & 2.7 & 4.8 & 2.55 & 32 & 26.2 & 5.1 & 14.1 & 2.7 & 5.5 \\
\hline $\begin{array}{l}\text { (Wenxin Tang et } \\
\text { al., 2016) }\end{array}$ & 18 & 27.3 & 10.4 & 13.5 & 2.4 & 8.1 & 5.7 & 16 & 26.8 & 9.8 & 13.5 & 2.4 & 5.4 \\
\hline $\begin{array}{l}\text { (Togao et al., } \\
2010 \text { ) }\end{array}$ & 16 & 32.8 & 7.5 & 14 & 1.6 & 12.09 & 8.5 & 32 & 32.6 & 8.7 & 14 & 1.6 & 5.05 \\
\hline $\begin{array}{l}\text { (Valente et al., } \\
\text { 2005) }\end{array}$ & 19 & 32.7 & 8.8 & 18.3 & & 18.3 & & 15 & 32.3 & 11.8 & 10.4 & NA & 24.6 \\
\hline (So et al., 2008a) & 71 & 26.6 & 7.49 & NA & & 8 & & 71 & 26.68 & 6.09 & NA & NA & 22.84 \\
\hline
\end{tabular}

n.P; the number of patients, M_ageP; mean age of patients, SD; standard deviation, Edu; mean education in years, Duration; mean duration of illness in years, n.C; the number of controls, NA; not applicable

Table 2Details of SUD category

\begin{tabular}{|c|c|c|c|c|c|c|c|}
\hline Category & SUD & & & & Controls & & \\
\hline & $\begin{array}{l}\text { No. } \\
\text { studies }\end{array}$ & Participants & $\begin{array}{l}\text { Mean } \\
\text { Age }\end{array}$ & $\begin{array}{l}\text { Standard } \\
\text { deviation }\end{array}$ & Participants & $\begin{array}{l}\text { Mean } \\
\text { Age }\end{array}$ & $\begin{array}{l}\text { Standard } \\
\text { deviation }\end{array}$ \\
\hline Alcohol & 12 & 308 & 45.4685 & 8.2472 & 336 & 42.9538 & 9.6344 \\
\hline Cocaine & 9 & 221 & 38.1661 & 9.2458 & 225 & 35.5804 & 9.2636 \\
\hline Nicotine & 10 & 662 & 38.1255 & 11.5931 & 1024 & 44.0869 & 15.917 \\
\hline
\end{tabular}

\subsection{Main GMV Results}




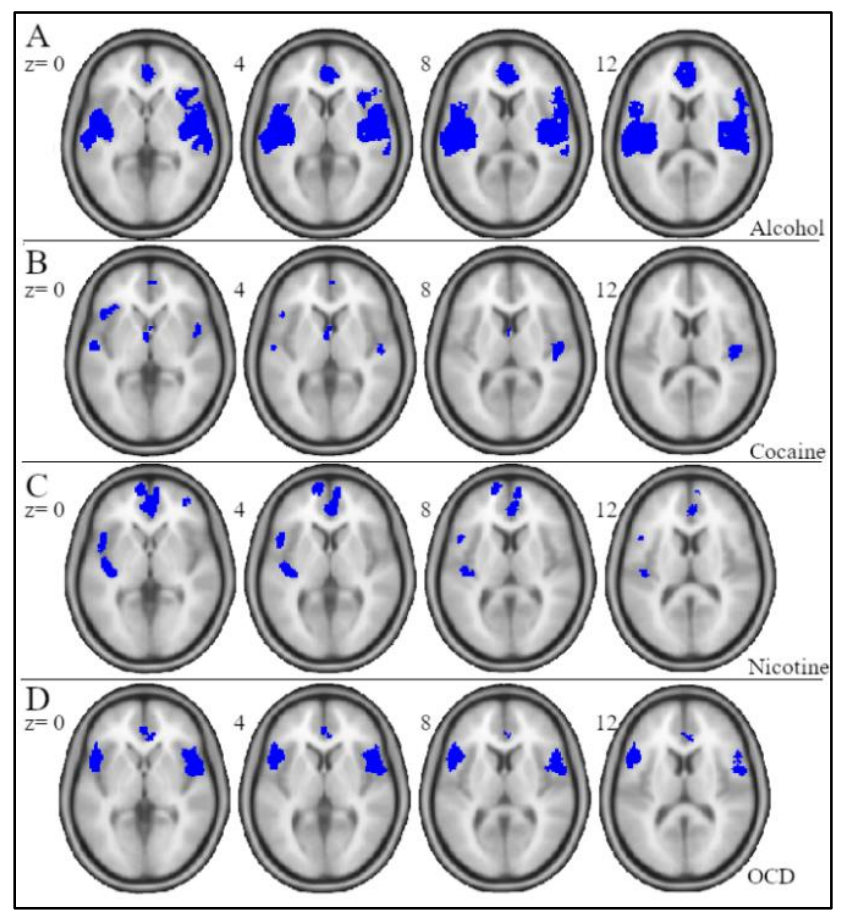

Figure 2Reduced GMV in each of the diagnostic group (patients $<$ controls), corrected at FWE $<0.05$

Results from the disorder-specific SDM-PSI meta-analysis are shown in Figure 2. After FWE correction was performed within each diagnostic category, reduced GMV for each diagnostic category as compared to healthy controls was mainly located in the bilateral anterior insula, and adjacent inferior frontal gyrus, dorsal anterior cingulate (dACC), and adjacent medial frontal gyrus (Figures 2A-D). All SUDs additionally exhibited reduced GMV of posterior insular regions (Figures 2A-C), while nicotine use disorder exhibited reduced GM in the left, but not the right anterior insula (Figure 1C,z=12). No regions with increased GMV were observed in any of the SUDs relative to healthy controls, whereas OCD showed increase GMV in the left striatum (putamen) (Figure 4B). An additional conjunction analysis in the three SUDs additionally revealed convergently decreased GMV in the left insula/IFG and the prefrontal cortex across the SUDs (results displayed in supplementary Figure 1). The conjunction analysis revealed that all four disorders exhibited convergently reduced GMV in the left inferior frontal gyrus (IFG) (Figure 3A). The detailed GMV changes in each disorder compared to healthy controls are presented in Supplementary Table 1-4. The results remained robust in the jackknife sensitivity analyses (Supplementary Table 5).

\subsection{Exploratory analyses: meta-regression and neural decoding}

To functionally characterize the region identified, a functional co-activation analysis was conducted. Coactivation analysis revealed that the identified IFG region primarily co-activated with broad regions of the frontal and parietal regions encompassing mainly the frontoparietal control network (Figure 3B). 


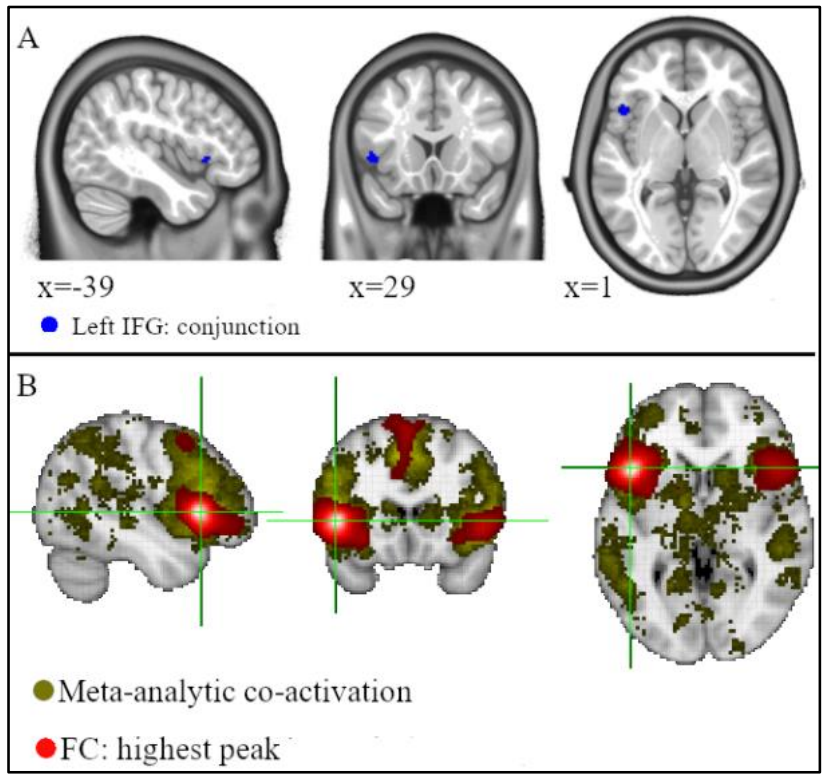

Figure 3Conjunction and meta-analytic co-activation analysis. A) Reduced GMV overlap among the four groups (Patients < controls), corrected at $\mathrm{FWE}<0.05$. B) shows regions coactivated with the seed (IFG)

The meta-regression revealed no significant associations (age, duration of substance use for SUD). However, in OCD, a significant association with symptom severity was found in the left dorsal striatum. Specifically, a higher OCD symptom as assessed by YBOCS scores were associated with increased left putamen GMV in the OCD patients (Figure 4A).

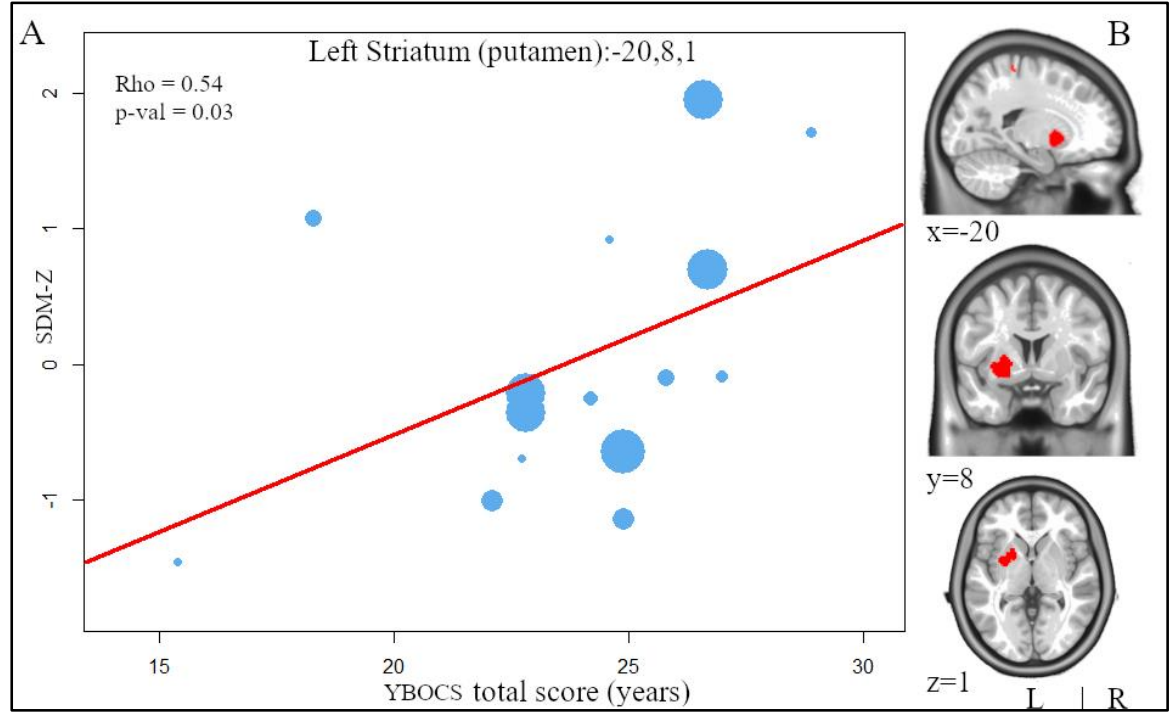

Figure 4Meta-regression. A) Meta-regression showing a relationship between OCD severity (measured using mean Yale-Brown Obsessive-Compulsive Scale (YBOCS) scale) and GMV in left putamen. Each dot shows studies included in the regression; the different sizes symbolizes greater sample sizes. The meta-regression SDM-Z values indicates the proportion of studies that reported GM alterations close to the voxel. B) Increase GMV in OCD: L. Putamen, corrected at FWE $<0.05$. Significant clusters were overlaid on an mni_icbm152 template for display purposes only 
medRxiv preprint doi: https://doi.org/10.1101/2020.09.03.20187229; this version posted September 3, 2020. The copyright holder for this preprint (which was not certified by peer review) is the author/funder, who has granted medRxiv a license to display the preprint in perpetuity.

It is made available under a CC-BY-NC 4.0 International license.

Findings from the GCA in the sample of healthy subjects revealed that causality was observed between the IFG and the striatum, specifically, an inflow pattern from left striatum regions to the IFG except for left dorsal putamen (dPu.L) (p<0.05), Figure 5A. Generally, the pattern of bidirectional causal flow indicated a higher inflow from the target regions to the IFG $(\mathrm{p}<0.05)$ with inflow/outflow between IFG and dCa.L showing the highest causality. In these results, we found that there was only positive NetFlow from the seed region to the left ventral putamen (vPu.L), signifying the causal influence from the IFG to this subregion of the striatum (Figure 5B).

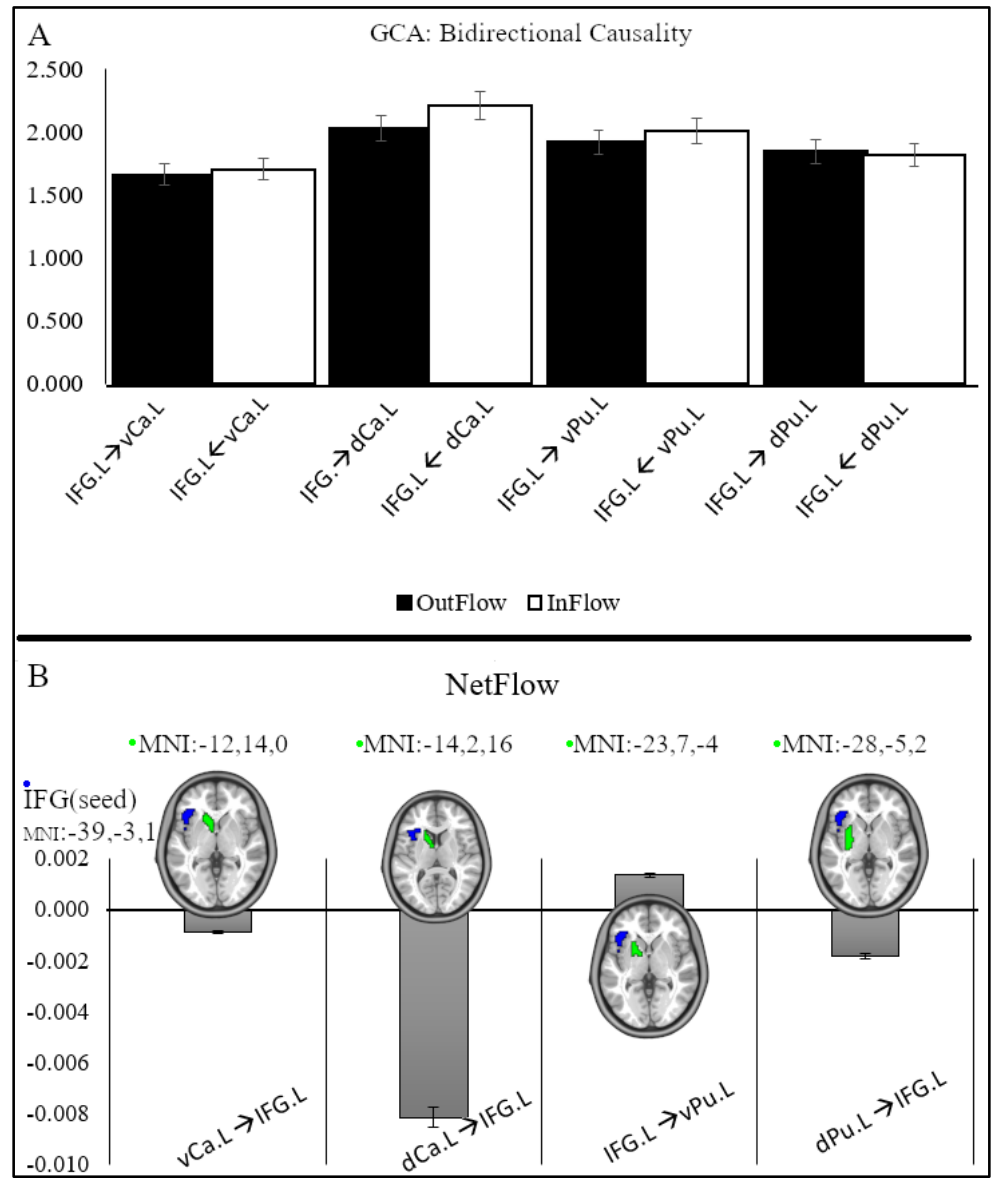

Figure 5 Causality between seed region and target ROls. A) Each group of bars represent GCA residual computation from seed region IFG to selected striatal regions and vice versa. B) the overall causality between the IFG and the striatum regions. Seed region computed from the conjunction GMV of all diagnostic disorders' $y$-axis values are the z-scores computed from the residual GCA. Target ROI extracted from Brain connectome project atlas. vCa; ventral caudate, dCa; dorsal caudate; vPu; ventral putamen, $\mathrm{dPu}$; dorsal putamen. The error bar shows the percentage standard error. $\mathrm{MNI}$ are the center location of the region 


\section{Discussion}

The present meta-analytic study examined for the first time shared GMV alterations between SUDs and OCD. The disorder-specific voxel-wise meta-analysis revealed widespread medial frontal and insular GMV reductions within the SUD and OCD compared to controls and the conjunction meta-analysis revealed that the disorders are transdiagnostically characterized by reduced GMV in the left IFG. Subsequent exploratory analysis that aimed at functionally characterizing the identified region revealed that the left IFG functionally co-activated with a broad network including bilateral parietal and frontal regions, suggesting that this region represents a core node in the frontoparietal control networks. Based on the consistently reported role of frontostriatal circuits in SUD as well as OCD the intrinsic causal influence of the identified IFG region over the striatum was examined in an independent dataset of healthy subjects and revealed that the causal influence propagated from the left striatum to the left IFG, whereas the IFG exerted causal influence over the ventral putamen. Finally, we found that only OCD exhibited increased GMV, specifically in the left dorsal striatum (putamen) which positively correlated with OCD symptom severity (as assessed by the YBOCs) in OCD. The findings generally remained robust when subjected to jackknife sensitivity analyses. Together, the meta-analytic approach allowed us to determine common GMV alterations between SUD and OCD which may underly the shared symptoms on the behavioral level, specifically compulsive behavior and loss of behavioral control which characterizes both disorders.

\subsection{Implications - SUD}

The frontocortical GMV decreases in the SUD groups broadly resemble findings from the previous metaand mega-analysis in subjects with SUD (e.g. (Ersche, Williams, Robbins, \& Bullmore, 2013; Mackey et al., 2019; Yang et al., 2016)). Across the SUDs examined, the insula showed marked decreases in the GMV. The insula alteration was functionally shown in our previous study suggesting common neurofunctional alterations in this region across SUDs (B. Klugah-Brown et al., 2020) as well as between SUDs and OCD (Klugah-brown et al., 2020). The insula has increasingly been noted as addiction relevant region, probably via its important role in interoceptive processing, decision making, and/or risky behavior which may promote substance abuse despite being aware of the negative consequences (B. Klugah-Brown et al., 2020; Naqvi \& Bechara, 2009). Structural deficit and/or functional alteration of the insula has been repeatedly described and associated with an increased relapse risk (Paulus, Tapert, \& Schulteis, 2009). Moreover, the SUDs were characterized by medial frontal GM decreases, a region involved in decision making, selfawareness and regulatory control, such that deficits in this region have been shown to promote dysregulated reinforcement (Bechara, Tranel, \& Damasio, 2009; Mackey et al., 2016). Decreased GMV in this network thus may neurally accompany the relationship between maladaptive decision, self-awareness and deficient regulatory control characterizing addictive disorders. 


\subsection{Implications - OCD}

In OCD, widespread regions of the bilateral insula and focused regions in the IFG as well as dorsal anterior cingulate exhibited decreased GMV. On the functional level, the frontocortical and cingulate regions have consistently been found to be disrupted in OCD patients relative to controls in a number of fMRI studies examining resting-state (Y. Cheng et al., 2013; de Vries et al., 2019; Swedo et al., 1989; Yun et al., 2017) and task-based (Friedman et al., 2017; Maltby, Tolin, Worhunsky, O’Keefe, \& Kiehl, 2005; Marsh et al., 2014; Yücel et al., 2007) neural activation. Our meta-analysis in OCD patients determined a decreased GMV in a similar network and previous studies have linked the identified network to cognitive control and inhibitory control mechanisms (Chamberlain, Blackwell, Fineberg, Robbins, \& Sahakian, 2005; Yücel et al., 2007). Additionally, our meta-regression revealed an association between higher symptom scores in OCD patients and GMV increases of the dorsal striatum (putamen), a region that has been previously reported in functional neuroimaging studies in OCD (Baxter et al., 1996; Rapoport \& Wise, 1988; Saxena, Brody, Schwartz, \& Baxter, 1998).

\subsection{Implications - common decreases in IFG GMV}

The principal aim of the present meta-analysis was to determine shared GMV alterations between the disorders to facilitate the identification of brain structural commonalities which may underpin compulsivity, thus representing a key transdiagnostic symptom across SUDs and OCD. The corresponding conjunction analysis revealed that the left IFG exhibited shared volumetric decreases across the disorders. The left insular and adjacent IFG is known to play an important role in regulatory top-down control, particularly response inhibition (Devito et al., 2013), a neurocognitive function that has been found to be impaired in both disorders and may promote the development of compulsive behavior (Chamberlain et al., 2005; Zilverstand, Huang, Alia-Klein, \& Goldstein, 2018). Moreover, the subsequent exploratory analysis that aimed at functionally characterizing this region suggests that the identified IFG region co-activates with widespread regions in the parietal and frontal cortex that highly resembles the front-parietal cognitive control network critically engaged in executive functions and behavioral control (Chen et al., 2018; Dixon et al., 2018; Fiske \& Holmboe, 2019; Gürsel, Avram, Sorg, Brandl, \& Koch, 2018; Reineberg, Gustavson, Benca, Banich, \& Friedman, 2018; Stern, Fitzgerald, Welsh, Abelson, \& Taylor, 2012). Based on previous conceptualizations and studies proposing a critical engagement of the frontostriatal circuits in both, SUD and OCD we employed GCA to examine the causal relationship between the identified IFG region and the striatum. Results confirmed a causal information flow between the two structures, specifically left striatal subregions causally influenced the IFG whereas the IFG controlled the ventral putamen. With respect to SUD, both the ventral striatal and the dorsal striatum have been engaged in maladaptive reward processing and the development of compulsive behavior (Andrews et al., 2011; Patel et al., 2013). Thus, the causal relationships and the main conjunction meta-analytic result support the suggestion that compulsivity and 
altered response to reward and/or punishment may be linked via these pathways that have been involved in both addiction and OCD. Interestingly previous studies have demonstrated shared alterations in this circuit between OCD and behavioral addiction (pathological gambling (Scherrer, Xian, Slutske, Eisen, \& Potenza, 2015)), suggesting a transdiagnostic functional dysregulation in these pathways and some previous deepbrain stimulation studies have shown that compulsive behavior in OCD and addiction can be significantly attenuated through decreasing frontostriatal connectivity (De Ridder, Vanneste, Kovacs, Sunaert, \& Dom, 2011; Dunlop et al., 2016; Figee et al., 2013; Kravitz et al., 2015; Valencia-Alfonso et al., 2012).

Summarizing, shared GMV loss in a region of the IFG which represents a principal node in the cognitive control network and critically interacts with the striatum may characterize addictive disorders and OCD and may underly the compulsive behavior exhibited by both disorders. The findings, therefore, resonate with previous conceptualizations proposing shared neurobiological alterations between the disorders that may promote the development of transdiagnostic symptoms of compulsivity.

It is noteworthy that, despite the important insights that the meta-analytic approach may have allowed, some limitations hindered the full examination of the topic. Firstly, only a limited number of VBM have been conducted in SUD resulting in a comparably low number of studies for the separate SUDs. However, across the separate SUDs convergent changes in the insula and prefrontal cortex were observed suggesting substance-independent GM alterations in SUD and pooling the data for the comparison with OCD increased the statistical power. Nevertheless, findings in the individual SUDs need to be interpreted cautiously. Secondly, since the disorders require different diagnostic symptom assessments, a meta-regression with severity measures could not be conducted across all disorders. Also, studies in each category did not report consistent measures (some studies did not report severity/duration and other measures). We, therefore, encourage researchers to report these measures as it reflects the core relationships between altered regions and symptoms.

\section{Conclusion}

We capitalized on previous case-control VBM studies in three prevalent SUDs and OCD with the aim to determine shared brain structural alterations across the disorders. The left IFG exhibited decreased GMV across all disorders suggesting a transdiagnostic marker that may underly the key symptomatic feature of compulsivity that characterizes the disorders. The IFG plays an important role in inhibitory control and our findings indicate that this region functionally interacts with both, the cognitive control network and the striatum, suggesting that this region plays a key role in the interaction between frontal regulatory control functions and habitual and reward-driven behavior. The findings emphasize that the symptomatological overlap may be rooted in common brain alterations and may open a new venue towards transdiagnostic treatment approaches that target brain alterations that promote compulsive behavior. 
medRxiv preprint doi: https://doi.org/10.1101/2020.09.03.20187229; this version posted September 3, 2020. The copyright holder for this preprint

(which was not certified by peer review) is the author/funder, who has granted medRxiv a license to display the preprint in perpetuity.

It is made available under a CC-BY-NC 4.0 International license.

\section{Acknowledgment}

This work was supported by the National Key Research and Development Program of China (Grant No.

2018YFA0701400), National Natural Science Foundation of China (NSFC, No 91632117), and Science, Innovation and Technology Department of the Sichuan Province (2018JY0001).

\section{Competing Interest Statement}

The authors have declared no competing interest 


\section{Reference}

Andrews, M. M., Meda, S. A., Thomas, A. D., Potenza, M. N., Krystal, J. H., Worhunsky, P., ...

Pearlson, G. D. (2011). Individuals family history positive for alcoholism show functional magnetic resonance imaging differences in reward sensitivity that are related to impulsivity factors. Biological Psychiatry, 69(7), 675-683. https://doi.org/10.1016/j.biopsych.2010.09.049

Bachi, K., Parvaz, M. A., Moeller, S. J., Gan, G., Zilverstand, A., Goldstein, R. Z., \& Alia-Klein, N. (2018). Reduced orbitofrontal gray matter concentration as a marker of premorbid childhood trauma in cocaine use disorder. Frontiers in Human Neuroscience, 12(February), 1-12. https://doi.org/10.3389/fnhum.2018.00051

Bari, A., \& Robbins, T. W. (2013). Inhibition and impulsivity: Behavioral and neural basis of response control. Progress in Neurobiology. https://doi.org/10.1016/j.pneurobio.2013.06.005

Barrós-Loscertales, A., Garavan, H., Bustamante, J. C., Ventura-Campos, N., Llopis, J. J., Belloch, V., ... Ávila, C. (2011). Reduced striatal volume in cocaine-dependent patients. NeuroImage, 56(3), 10211026. https://doi.org/10.1016/j.neuroimage.2011.02.035

Baxter, Saxena, Brody, Ackermann, Colgan, Schwartz, ... Phelps. (1996). Brain mediation of obsessivecompulsive disorder symptoms: evidence from functional brain imaging studies in the human and nonhuman primate. Seminars in Clinical Neuropsychiatry. https://doi.org/10.1053/SCNP00100032

Bechara, A., Tranel, D., \& Damasio, H. (2009). Characterization of the decision-making deficit of patients with ventromedial prefrontal cortex lesions (Brain (2000) 123 (2189-2202) DOI:10.1093/brain/123.11.2189). Brain. https://doi.org/10.1093/brain/awp122

Bellini, S., Fleming, K. E., De, M., McCauley, J. P., Petroccione, M. A., D’Brant, L. Y., ... Scimemi, A. (2018). Neuronal glutamate transporters control dopaminergic signaling and compulsive behaviors. Journal of Neuroscience. https://doi.org/10.1523/JNEUROSCI.1906-17.2017

Blom, R. M., Koeter, M., van den Brink, W., de Graaf, R., ten Have, M., \& Denys, D. (2011). Cooccurrence of obsessive-compulsive disorder and substance use disorder in the general population. Addiction. https://doi.org/10.1111/j.1360-0443.2011.03559.x

Britton, J. C., Rauch, S. L., Rosso, I. M., Killgore, W. D. S., Price, L. M., Ragan, J., .. Stewart, S. E. (2010). Cognitive inflexibility and frontal-cortical activation in pediatric obsessive-compulsive disorder. Journal of the American Academy of Child and Adolescent Psychiatry, 49(9), 944-953. https://doi.org/10.1016/j.jaac.2010.05.006 
Brody, A. L., Mandelkern, M. A., Jarvik, M. E., Lee, G. S., Smith, E. C., Huang, J. C., ... London, E. D. (2004). Differences between smokers and nonsmokers in regional gray matter volumes and densities. Biological Psychiatry, 55(1), 77-84. https://doi.org/10.1016/S0006-3223(03)00610-3

Button, K. S., Ioannidis, J. P. A., Mokrysz, C., Nosek, B. A., Flint, J., Robinson, E. S. J., \& Munafò, M. R. (2013). Power failure: Why small sample size undermines the reliability of neuroscience. Nature Reviews Neuroscience. https://doi.org/10.1038/nrn3475

Carmona, S., Bassas, N., Rovira, M., Gispert, J. D., Soliva, J. C., Prado, M., ... Vilarroya, O. (2007). Pediatric OCD structural brain deficits in conflict monitoring circuits: A voxel-based morphometry study. Neuroscience Letters, 421(3), 218-223. https://doi.org/10.1016/j.neulet.2007.05.047

Chamberlain, S. R., Blackwell, A. D., Fineberg, N. A., Robbins, T. W., \& Sahakian, B. J. (2005). The neuropsychology of obsessive compulsive disorder: The importance of failures in cognitive and behavioural inhibition as candidate endophenotypic markers. Neuroscience and Biobehavioral Reviews. https://doi.org/10.1016/j.neubiorev.2004.11.006

Chanraud, S., Leroy, C., Martelli, C., Kostogianni, N., Delain, F., Aubin, H. J., .. Martinot, J. L. (2009). Episodic memory in detoxified alcoholics: Contribution of grey matter microstructure alteration. PLoS ONE, 4(8). https://doi.org/10.1371/journal.pone.0006786

Chanraud, S., Martelli, C., Delain, F., Kostogianni, N., Douaud, G., Aubin, H. J., .. Martinot, J. L. (2007). Brain morphometry and cognitive performance in detoxified alcohol-dependents with preserved psychosocial functioning. Neuropsychopharmacology, 32(2), 429-438. https://doi.org/10.1038/sj.npp.1301219

Chen, Y. H., Li, S. F., Lv, D., Zhu, G. D., Wang, Y. H., Meng, X., ... Li, P. (2018). Decreased intrinsic functional connectivity of the salience network in drug-naive patients with obsessive-compulsive disorder. Frontiers in Neuroscience. https://doi.org/10.3389/fnins.2018.00889

Cheng, B., Cai, W., Wang, X., Lei, D., Guo, Y., Yang, X., ... Ning, G. (2016). Brain gray matter abnormalities in first-episode, treatment-naive children with obsessive-compulsive disorder. Frontiers in Behavioral Neuroscience, 10(Jun), 1-8. https://doi.org/10.3389/fnbeh.2016.00141

Cheng, Y., Xu, J., Nie, B., Luo, C., Yang, T., Li, H., ... Xu, X. (2013). Abnormal Resting-State Activities and Functional Connectivities of the Anterior and the Posterior Cortexes in Medication-Naïve Patients with Obsessive-Compulsive Disorder. PLOS ONE. https://doi.org/10.1371/journal.pone.0067478 
Christian, C. J., Lencz, T., Robinson, D. G., Burdick, K. E., Ashtari, M., Malhotra, A. K., .. Szeszko, P. R. (2008). Gray matter structural alterations in obsessive-compulsive disorder: Relationship to neuropsychological functions. Psychiatry Research - Neuroimaging. https://doi.org/10.1016/j.pscychresns.2008.03.005

Cools, R. (2008). Role of dopamine in the motivational and cognitive control of behavior. Neuroscientist, 14(4), 381-395. https://doi.org/10.1177/1073858408317009

Cousijn, J., Wiers, R. W., Ridderinkhof, K. R., Van den Brink, W., Veltman, D. J., \& Goudriaan, A. E. (2012). Grey matter alterations associated with cannabis use: Results of a VBM study in heavy cannabis users and healthy controls. NeuroImage. https://doi.org/10.1016/j.neuroimage.2011.09.046

Crunelle, C. L., Kaag, A. M., van Wingen, G., van den Munkhof, H. E., Homberg, J. R., Reneman, L., \& van den Brink, W. (2014). Reduced frontal brain volume in non-treatment-seeking cocainedependent individuals: Exploring the role of impulsivity, depression, and smoking. Frontiers in Human Neuroscience. https://doi.org/10.3389/fnhum.2014.00007

De Ridder, D., Vanneste, S., Kovacs, S., Sunaert, S., \& Dom, G. (2011). Transient alcohol craving suppression by rTMS of dorsal anterior cingulate: An fMRI and LORETA EEG study. Neuroscience Letters, 496(1), 5-10. https://doi.org/10.1016/j.neulet.2011.03.074

de Vries, F. E., de Wit, S. J., van den Heuvel, O. A., Veltman, D. J., Cath, D. C., van Balkom, A. J. L. M., \& van der Werf, Y. D. (2019). Cognitive control networks in OCD: A resting-state connectivity study in unmedicated patients with obsessive-compulsive disorder and their unaffected relatives. World Journal of Biological Psychiatry. https://doi.org/10.1080/15622975.2017.1353132

de Wit, S. J., Alonso, P., Schweren, L., Mataix-Cols, D., Lochner, C., Menchón, J. M., ... van den Heuvel, O. A. (2015). Multicenter Voxel-Based Morphometry Mega-Analysis of Structural Brain Scans in Obsessive-Compulsive Disorder. Focus, 13(2), 204-212. https://doi.org/10.1176/appi.focus.130210

Demirakca, T., Ende, G., Kämmerer, N., Welzel-Marquez, H., Hermann, D., Heinz, A., \& Mann, K. (2011). Effects of alcoholism and continued abstinence on brain volumes in both genders. Alcoholism: Clinical and Experimental Research, 35(9), 1678-1685. https://doi.org/10.1111/j.15300277.2011.01514.x

Devito, E. E., Meda, S. A., Jiantonio, R., Potenza, M. N., Krystal, J. H., \& Pearlson, G. D. (2013). Neural correlates of impulsivity in healthy males and females with family histories of alcoholism. Neuropsychopharmacology, 38(10), 1854-1863. https://doi.org/10.1038/npp.2013.92 
Dixon, M. L., De La Vega, A., Mills, C., Andrews-Hanna, J., Spreng, R. N., Cole, M. W., \& Christoff, K. (2018). Heterogeneity within the frontoparietal control network and its relationship to the default and dorsal attention networks. Proceedings of the National Academy of Sciences of the United States of America. https://doi.org/10.1073/pnas.1715766115

Dunlop, K., Woodside, B., Olmsted, M., Colton, P., Giacobbe, P., \& Downar, J. (2016). Reductions in Cortico-Striatal Hyperconnectivity Accompany Successful Treatment of Obsessive-Compulsive Disorder with Dorsomedial Prefrontal rTMS. Neuropsychopharmacology, 41(5), 1395-1403. https://doi.org/10.1038/npp.2015.292

Ersche, K. D., Williams, G. B., Robbins, T. W., \& Bullmore, E. T. (2013). Meta-analysis of structural brain abnormalities associated with stimulant drug dependence and neuroimaging of addiction vulnerability and resilience. Current Opinion in Neurobiology. https://doi.org/10.1016/j.conb.2013.02.017

Everitt, B. J., \& Robbins, T. W. (2005). Neural systems of reinforcement for drug addiction: From actions to habits to compulsion. Nature Neuroscience. https://doi.org/10.1038/nn1579

Figee, M., Luigjes, J., Smolders, R., Valencia-Alfonso, C. E., Van Wingen, G., De Kwaasteniet, B., ... Denys, D. (2013). Deep brain stimulation restores frontostriatal network activity in obsessivecompulsive disorder. Nature Neuroscience. https://doi.org/10.1038/nn.3344

Fiske, A., \& Holmboe, K. (2019). Neural substrates of early executive function development. Developmental Review. https://doi.org/10.1016/j.dr.2019.100866

Franklin, T. R., Acton, P. D., Maldjian, J. A., Gray, J. D., Croft, J. R., Dackis, C. A., .. Childress, A. R. (2002). Decreased Gray Matter Concentration in the Insular, Cocaine Patients. Biological Psychiatry, 51(01), 134-142.

Franklin, T. R., Wetherill, R. R., Jagannathan, K., Johnson, B., Mumma, J., Hager, N., .. Childress, A. R. (2014). The effects of chronic cigarette smoking on gray matter volume: Influence of sex. PLoS ONE, 9(8), 1-7. https://doi.org/10.1371/journal.pone.0104102

Friedman, A. L., Burgess, A., Ramaseshan, K., Easter, P., Khatib, D., Chowdury, A., ... Diwadkar, V. A. (2017). Brain network dysfunction in youth with obsessive-compulsive disorder induced by simple uni-manual behavior: The role of the dorsal anterior cingulate cortex. Psychiatry Research Neuroimaging. https://doi.org/10.1016/j.pscychresns.2016.12.005

Fritz, H. C., Wittfeld, K., Schmidt, C. O., Domin, M., Grabe, H. J., Hegenscheid, K., ... Lotze, M. (2014). 
Current smoking and reduced gray matter volume - A voxel-based morphometry study. Neuropsychopharmacology, 39(11), 2594-2600. https://doi.org/10.1038/npp.2014.112

Galandra, C., Basso, G., Manera, M., Crespi, C., Giorgi, I., Vittadini, G., ... Canessa, N. (2018). Salience network structural integrity predicts executive impairment in alcohol use disorders. Scientific Reports, 8(1), 1-13. https://doi.org/10.1038/s41598-018-32828-x

Galandra, C., Crespi, C., Basso, G., Manera, M. R., Giorgi, I., Poggi, P., \& Canessa, N. (2020). Decreased information processing speed and decision-making performance in alcohol use disorder: combined neurostructural evidence from VBM and TBSS. Brain Imaging and Behavior. https://doi.org/10.1007/s11682-019-00248-8

Gallinat, J., Meisenzahl, E., Jacobsen, L. K., Kalus, P., Bierbrauer, J., Kienast, T., ... Staedtgen, M. (2006). Smoking and structural brain deficits: A volumetric MR investigation. European Journal of Neuroscience, 24(6), 1744-1750. https://doi.org/10.1111/j.1460-9568.2006.05050.x

Gardini, S., \& Venneri, A. (2012). Reduced grey matter in the posterior insula as a structural vulnerability or diathesis to addiction. Brain Research Bulletin, 87(2-3), 205-211. https://doi.org/10.1016/j.brainresbull.2011.11.021

Gass, J. T., \& Olive, M. F. (2008). Glutamatergic substrates of drug addiction and alcoholism. Biochemical Pharmacology. https://doi.org/10.1016/j.bcp.2007.06.039

Gilbert, A. R., Keshavan, M. S., Diwadkar, V., Nutche, J., MacMaster, F., Easter, P. C., ... Rosenberg, D. R. (2008). Gray matter differences between pediatric obsessive-compulsive disorder patients and high-risk siblings: A preliminary voxel-based morphometry study. Neuroscience Letters, 435(1), 45-50. https://doi.org/10.1016/j.neulet.2008.02.011

Gilbert, A. R., Mataix-Cols, D., Almeida, J. R. C., Lawrence, N., Nutche, J., Diwadkar, V., ... Phillips, M. L. (2008). Brain structure and symptom dimension relationships in obsessive-compulsive disorder: A voxel-based morphometry study. Journal of Affective Disorders, 109(1-2), 117-126. https://doi.org/10.1016/j.jad.2007.12.223

Glazier, K., Calixte, R. M., Rothschild, R., \& Pinto, A. (2013). High rates of OCD symptom misidentification by mental health professionals. Annals of Clinical Psychiatry.

Goldstein, R. Z., Craig, A. D. (Bud., Bechara, A., Garavan, H., Childress, A. R., Paulus, M. P., \& Volkow, N. D. (2009). The Neurocircuitry of Impaired Insight in Drug Addiction. Trends in Cognitive Sciences. https://doi.org/10.1016/j.tics.2009.06.004 
Gonçalves, Ó. F., Carvalho, S., Leite, J., Fernandes-Gonçalves, A., Carracedo, A., \& Sampaio, A. (2016). Cognitive and emotional impairments in obsessive-compulsive disorder: Evidence from functional brain alterations. Porto Biomedical Journal. https://doi.org/10.1016/j.pbj.2016.07.005

Gonçalves, O. F., Sousa, S., Carvalho, S., Leite, J., Ganho, A., Fernandes-Gonçalves, A., ... Sampaio, A. (2017). Alterations of gray and white matter morphology in obsessive compulsive disorder. Psicothema. https://doi.org/10.7334/psicothema2016.86

Gürsel, D. A., Avram, M., Sorg, C., Brandl, F., \& Koch, K. (2018). Frontoparietal areas link impairments of large-scale intrinsic brain networks with aberrant fronto-striatal interactions in OCD: a metaanalysis of resting-state functional connectivity. Neuroscience and Biobehavioral Reviews. https://doi.org/10.1016/j.neubiorev.2018.01.016

Hanlon, C. A., Dufault, D. L., Wesley, M. J., \& Porrino, L. J. (2011). Elevated gray and white matter densities in cocaine abstainers compared to current users. Psychopharmacology, 218(4), 681-692. https://doi.org/10.1007/s00213-011-2360-y

Hanlon, C. A., Owens, M. M., Joseph, J. E., Zhu, X., George, M. S., Brady, K. T., \& Hartwell, K. J. (2016). Lower subcortical gray matter volume in both younger smokers and established smokers relative to non-smokers. Addiction Biology, 21(1), 185-195. https://doi.org/10.1111/adb.12171

Hashimoto, N., Nakaaki, S., Kawaguchi, A., Sato, J., Kasai, H., Nakamae, T., ... Mimura, M. (2014). Brain structural abnormalities in behavior therapy-resistant obsessive-compulsive disorder revealed by voxel-based morphometry. Neuropsychiatric Disease and Treatment, 10, 1987-1996. https://doi.org/10.2147/NDT.S69652

Ide, J. S., Zhang, S., Hu, S., Sinha, R., Mazure, C. M., \& Li, C. shan R. (2014). Cerebral gray matter volumes and low-frequency fluctuation of BOLD signals in cocaine dependence: Duration of use and gender difference. Drug and Alcohol Dependence. https://doi.org/10.1016/j.drugalcdep.2013.09.004

Ioannidis, J. P. A. (2011). Excess significance bias in the literature on brain volume abnormalities. Archives of General Psychiatry. https://doi.org/10.1001/archgenpsychiatry.2011.28

Jang, D. P., Namkoong, K., Kim, J. J., Park, S., Kim, I. Y., Kim, S. I., .. Lee, E. (2007). The relationship between brain morphometry and neuropsychological performance in alcohol dependence. Neuroscience Letters, 428(1), 21-26. https://doi.org/10.1016/j.neulet.2007.09.047

Kim, J., Myung Chul Lee, Kim, J., In Young Kim, Kim, S. I., Moon Hee Han, ... Jun Soo Kwon. (2001). 
Grey matter abnormalities in obsessive-compulsive disorder: Statistical parametric mapping of segmented magnetic resonance images. British Journal of Psychiatry.

https://doi.org/10.1192/bjp.179.4.330

Klugah-Brown, B., Di, X., Zweerings, J., Mathiak, K., Becker, B., \& Biswal, B. (2020). Common and separable neural alterations in substance use disorders: evidence from coordinate-based metaanalyses of functional neuroimaging studies in human. BioRxiv.

Klugah-brown, B., Zhou, X., Pradhan, B. K., Zweerings, J., Mathiak, K., \& Becker, B. (2020). Common and separable neurofunctional dysregulations characterize obsessive-compulsive, substance use, and gaming disorders - evidence from an activation likelihood meta-analysis of functional imaging studies.

Klugah-Brown, Benjamin, Luo, C., Peng, R., He, H., Li, J., Dong, L., \& Yao, D. (2019). Altered structural and causal connectivity in frontal lobe epilepsy. BMC Neurology. https://doi.org/10.1186/s12883-019-1300-z

Kobayashi, T., Hirano, Y., Nemoto, K., Sutoh, C., Ishikawa, K., Miyata, H., ... Nakagawa, A. (2015). Correlation between morphologic changes and autism spectrum tendency in obsessive-compulsive disorder. Magnetic Resonance in Medical Sciences, 14(4), 329-335. https://doi.org/10.2463/mrms.2014-0146

Koob, G. F., \& Volkow, N. D. (2010). Neurocircuitry of addiction. Neuropsychopharmacology, 35(1), 217-238. https://doi.org/10.1038/npp.2009.110

Kopřivová, J., Horáček, J., Tintěra, J., Praško, J., Raszka, M., Ibrahim, I., \& Höschl, C. (2009). Medial frontal and dorsal cortical morphometric abnormalities are related to obsessive-compulsive disorder. Neuroscience Letters, 464(1), 62-66. https://doi.org/10.1016/j.neulet.2009.08.012

Kravitz, A. V., Tomasi, D., Leblanc, K. H., Baler, R., Volkow, N. D., Bonci, A., \& Ferré, S. (2015). Cortico-striatal circuits: Novel therapeutic targets for substance use disorders. Brain Research, 1628, 186-198. https://doi.org/10.1016/j.brainres.2015.03.048

Lázaro, L., Castro-Fornieles, J., Cullell, C., Andrés, S., Falcón, C., Calvo, R., \& Bargalló, N. (2011). A voxel-based morphometric MRI study of stabilized obsessive-compulsive adolescent patients. Progress in Neuro-Psychopharmacology and Biological Psychiatry, 35(8), 1863-1869. https://doi.org/10.1016/j.pnpbp.2011.07.016

Liao, Y., Tang, J., Liu, T., Chen, X., \& Hao, W. (2012). Differences between smokers and non-smokers 
in regional gray matter volumes: A voxel-based morphometry study. Addiction Biology, 17(6), 977980. https://doi.org/10.1111/j.1369-1600.2010.00250.x

Liu, C., Xu, L., Li, J., Zhou, F., Yang, X., Zheng, X., ... Becker, B. (2019). Serotonin and early life stress interact to shape brain architecture and anxious avoidant behavior - a TPH2 imaging genetics approach. https://doi.org/10.1101/685099

Lochner, C., Fineberg, N. A., Zohar, J., Van Ameringen, M., Juven-Wetzler, A., Altamura, A. C., ... Stein, D. J. (2014). Comorbidity in obsessive-compulsive disorder (OCD): A report from the International College of Obsessive-Compulsive Spectrum Disorders (ICOCS). Comprehensive Psychiatry, 55(7), 1513-1519. https://doi.org/10.1016/j.comppsych.2014.05.020

Mackey, S., Allgaier, N., Chaarani, B., Spechler, P., Orr, C., Bunn, J., ... Garavan, H. (2019). Megaanalysis of gray matter volume in substance dependence: General and substance-specific regional effects. American Journal of Psychiatry. https://doi.org/10.1176/appi.ajp.2018.17040415

Mackey, S., Olafsson, V., Aupperle, R. L., Lu, K., Fonzo, G. A., Parnass, J., ... Paulus, M. P. (2016). Greater preference consistency during the Willingness-to-Pay task is related to higher resting state connectivity between the ventromedial prefrontal cortex and the ventral striatum. Brain Imaging and Behavior. https://doi.org/10.1007/s11682-015-9435-z

Maltby, N., Tolin, D. F., Worhunsky, P., O’Keefe, T. M., \& Kiehl, K. A. (2005). Dysfunctional action monitoring hyperactivates frontal-striatal circuits in obsessive-compulsive disorder: An eventrelated fMRI study. NeuroImage. https://doi.org/10.1016/j.neuroimage.2004.08.041

Mancebo, M. C., Grant, J. E., Pinto, A., Eisen, J. L., \& Rasmussen, S. A. (2009). Substance use disorders in an obsessive compulsive disorder clinical sample. Journal of Anxiety Disorders, 23(4), 429-435. https://doi.org/10.1016/j.janxdis.2008.08.008

Marsh, R., Horga, G., Parashar, N., Wang, Z., Peterson, B. S., \& Simpson, H. B. (2014). Altered activation in fronto-striatal circuits during sequential processing of conflict in unmedicated adults with obsessive-compulsive disorder. Biological Psychiatry. https://doi.org/10.1016/j.biopsych.2013.02.004

Matsumoto, R., Ito, H., Takahashi, H., Ando, T., Fujimura, Y., Nakayama, K., ... Suhara, T. (2010). Reduced gray matter volume of dorsal cingulate cortex in patients with obsessive-compulsive disorder: A voxel-based morphometric study. Psychiatry and Clinical Neurosciences, 64(5), 541547. https://doi.org/10.1111/j.1440-1819.2010.02125.x 
Mechtcheriakov, S., Brenneis, C., Egger, K., Koppelstaetter, F., Schocke, M., \& Marksteiner, J. (2007). A widespread distinct pattern of cerebral atrophy in patients with alcohol addiction revealed by voxelbased morphometry. Journal of Neurology, Neurosurgery and Psychiatry, 78(6), 610-614. https://doi.org/10.1136/jnnp.2006.095869

Milad, M. R., \& Rauch, S. L. (2012). Obsessive-compulsive disorder: Beyond segregated cortico-striatal pathways. Trends in Cognitive Sciences. https://doi.org/10.1016/j.tics.2011.11.003

Moher, D., Liberati, A., Tetzlaff, J., Altman, D. G., Antes, G., Atkins, D., ... Tugwell, P. (2014). Preferred Reporting Items for Systematic Reviews and Meta-Analyses: The PRISMA Statement. Revista Espanola de Nutricion Humana y Dietetica. https://doi.org/10.14306/renhyd.18.3.114

Moon, C. M., \& Jeong, G. W. (2018). Associations of neurofunctional, morphometric and metabolic abnormalities with clinical symptom severity and recognition deficit in obsessive-compulsive disorder. Journal of Affective Disorders, 227(May 2017), 603-612. https://doi.org/10.1016/j.jad.2017.11.059

Morales, A. M., Lee, B., Hellemann, G., O’Neill, J., \& London, E. D. (2012). Gray-matter volume in methamphetamine dependence: Cigarette smoking and changes with abstinence from methamphetamine. Drug and Alcohol Dependence, 125(3), 230-238. https://doi.org/10.1016/j.drugalcdep.2012.02.017

Moreira, P. S., Marques, P., Soriano-Mas, C., Magalhães, R., Sousa, N., Soares, J. M., \& Morgado, P. (2017). The neural correlates of obsessive-compulsive disorder: a multimodal perspective. Translational Psychiatry, 7(8), e1224. https://doi.org/10.1038/tp.2017.189

Müller, V. I., Cieslik, E. C., Laird, A. R., Fox, P. T., Radua, J., Mataix-Cols, D., ... Eickhoff, S. B. (2018). Ten simple rules for neuroimaging meta-analysis. Neuroscience and Biobehavioral Reviews, 84(November 2017), 151-161. https://doi.org/10.1016/j.neubiorev.2017.11.012

Naqvi, N. H., \& Bechara, A. (2009). The hidden island of addiction: the insula. Trends in Neurosciences. https://doi.org/10.1016/j.tins.2008.09.009

Nurmedov, S., Noyan, O., Metin, B., Ekmen, S., Avcil, C., \& Kose, S. (2016). Extensive gray matter volume reduction and correlations with neuropsychological performance in alcohol use disorder patients. Klinik Psikofarmakoloji Bulteni, 26(4), 355-363.

https://doi.org/10.5455/bcp.20160223123949

Okada, K., Nakao, T., Sanematsu, H., Murayama, K., Honda, S., Tomita, M., ... Kanba, S. (2015). 
Biological heterogeneity of obsessive-compulsive disorder: A voxel-based morphometric study based on dimensional assessment. Psychiatry and Clinical Neurosciences, 69(7), 411-421. https://doi.org/10.1111/pen.12269

Parvaz, M. A., Moeller, S. J., d'Oleire Uquillas, F., Pflumm, A., Maloney, T., Alia-Klein, N., \& Goldstein, R. Z. (2017). Prefrontal gray matter volume recovery in treatment-seeking cocaineaddicted individuals: a longitudinal study. Addiction Biology, 22(5), 1391-1401. https://doi.org/10.1111/adb.12403

Patel, K. T., Stevens, M. C., Meda, S. A., Muska, C., Thomas, A. D., Potenza, M. N., \& Pearlson, G. D. (2013). Robust changes in reward circuitry during reward loss in current and former cocaine users during performance of a monetary incentive delay task. Biological Psychiatry, 74(7), 529-537. https://doi.org/10.1016/j.biopsych.2013.04.029

Paulus, M. P., Tapert, S. F., \& Schulteis, G. (2009). The role of interoception and alliesthesia in addiction. Pharmacology Biochemistry and Behavior. https://doi.org/10.1016/j.pbb.2009.08.005

Peng, P., Wang, Z., Jiang, T., Chu, S., Wang, S., \& Xiao, D. (2017). Brain-volume changes in young and middle-aged smokers: a DARTEL-based voxel-based morphometry study. Clinical Respiratory Journal, 11(5), 621-631. https://doi.org/10.1111/crj.12393

Pittenger, C., Bloch, M. H., \& Williams, K. (2011). Glutamate abnormalities in obsessive compulsive disorder: Neurobiology, pathophysiology, and treatment. Pharmacology and Therapeutics. https://doi.org/10.1016/j.pharmthera.2011.09.006

Pujol, J., Soriano-Mas, C., Alonso, P., Cardoner, N., Menchón, J. M., Deus, J., \& Vallejo, J. (2004). Mapping structural brain alterations in obsessive-compulsive disorder. Archives of General Psychiatry. https://doi.org/10.1001/archpsyc.61.7.720

Radua, J., Van Den Heuvel, O. A., Surguladze, S., \& Mataix-Cols, D. (2010). Meta-analytical comparison of voxel-based morphometry studies in obsessive-compulsive disorder vs other anxiety disorders. Archives of General Psychiatry. https://doi.org/10.1001/archgenpsychiatry.2010.70

Rando, K., Tuit, K., Hannestad, J., Guarnaccia, J., \& Sinha, R. (2013). Sex differences in decreased limbic and cortical grey matter volume in cocaine dependence: A voxel-based morphometric study. Addiction Biology. https://doi.org/10.1111/adb.12008

Rapoport, J. L., \& Wise, S. P. (1988). Obsessive-compulsive disorder: Evidence for basal ganglia dysfunction. Psychopharmacology Bulletin. 
Reineberg, A. E., Gustavson, D. E., Benca, C., Banich, M. T., \& Friedman, N. P. (2018). The relationship between resting state network connectivity and individual differences in executive functions. Frontiers in Psychology. https://doi.org/10.3389/fpsyg.2018.01600

Robbins, T. W., Gillan, C. M., Smith, D. G., de Wit, S., \& Ersche, K. D. (2012). Neurocognitive endophenotypes of impulsivity and compulsivity: Towards dimensional psychiatry. Trends in Cognitive Sciences, 16(1), 81-91. https://doi.org/10.1016/j.tics.2011.11.009

Robbins, T. W., Vaghi, M. M., \& Banca, P. (2019). Obsessive-Compulsive Disorder: Puzzles and Prospects. Neuron, 102(1), 27-47. https://doi.org/10.1016/j.neuron.2019.01.046

Rotge, J. Y., Langbour, N., Guehl, D., Bioulac, B., Jaafari, N., Allard, M., ... Burbaud, P. (2010). Gray matter alterations in obsessive-compulsive disorder: An anatomic likelihood estimation metaanalysis. Neuropsychopharmacology. https://doi.org/10.1038/npp.2009.175

Ruscio, A. M., Stein, D. J., Chiu, W. T., \& Kessler, R. C. (2010). The epidemiology of obsessivecompulsive disorder in the National Comorbidity Survey Replication. Molecular Psychiatry. https://doi.org/10.1038/mp.2008.94

Saxena, S., Brody, A. L., Schwartz, J. M., \& Baxter, L. R. (1998). Neuroimaging and frontal-subcortical circuitry in obsessive-compulsive disorder. British Journal of Psychiatry. https://doi.org/10.1192/s0007125000297870

Scherrer, J. F., Xian, H., Slutske, W. S., Eisen, S. A., \& Potenza, M. N. (2015). Associations between obsessive-compulsive classes and pathological gambling in a national cohort of male twins. JAMA Psychiatry. https://doi.org/10.1001/jamapsychiatry.2014.2497

Segobin, S. H., Chételat, G., Le Berre, A. P., Lannuzel, C., Boudehent, C., Vabret, F., .. Pitel, A. L. (2014). Relationship between brain volumetric changes and interim drinking at six months in alcohol-dependent patients. Alcoholism: Clinical and Experimental Research, 38(3), 739-748. https://doi.org/10.1111/acer.12300

Sim, M. E., Lyoo, I. K., Streeter, C. C., Covell, J., Sarid-Segal, O., Ciraulo, D. A., ... Renshaw, P. F. (2007). Cerebellar gray matter volume correlates with duration of cocaine use in cocaine-dependent subjects. Neuropsychopharmacology, 32(10), 2229-2237. https://doi.org/10.1038/sj.npp.1301346

So, Y. Y., Roh, M. S., Choi, J. S., Kang, D. H., Tae, H. H., Lee, J. M., ... Jun, S. K. (2008a). Voxel-based morphometry study of gray matter abnormalities in obsessive-compulsive disorder. Journal of Korean Medical Science. https://doi.org/10.3346/jkms.2008.23.1.24 
So, Y. Y., Roh, M. S., Choi, J. S., Kang, D. H., Tae, H. H., Lee, J. M., ... Jun, S. K. (2008b). Voxel-based morphometry study of gray matter abnormalities in obsessive-compulsive disorder. Journal of Korean Medical Science, 23(1), 24-30. https://doi.org/10.3346/jkms.2008.23.1.24

Soriano-Mas, C., Pujol, J., Alonso, P., Cardoner, N., Menchón, J. M., Harrison, B. J., ... Gaser, C. (2007). Identifying patients with obsessive-compulsive disorder using whole-brain anatomy. NeuroImage. https://doi.org/10.1016/j.neuroimage.2007.01.011

Stern, E. R., Fitzgerald, K. D., Welsh, R. C., Abelson, J. L., \& Taylor, S. F. (2012). Resting-state functional connectivity between fronto-parietal and default mode networks in obsessive-compulsive disorder. PLoS ONE. https://doi.org/10.1371/journal.pone.0036356

Subirà, M., Alonso, P., Segalàs, C., Real, E., López-Solà, C., Pujol, J., ... Soriano-Mas, C. (2013). Brain Structural Alterations in Obsessive-Compulsive Disorder Patients with Autogenous and Reactive Obsessions. PLoS ONE, 8(9). https://doi.org/10.1371/journal.pone.0075273

Subirà, M., Sato, J. R., Alonso, P., do Rosário, M. C., Segalàs, C., Batistuzzo, M. C., ... Soriano-Mas, C. (2015). Brain structural correlates of sensory phenomena in patients with obsessive-Compulsive disorder. Journal of Psychiatry and Neuroscience, 40(4), 232-240. https://doi.org/10.1503/jpn.140118

Swedo, S. E., Schapiro, M. B., Grady, C. L., Cheslow, D. L., Leonard, H. L., Kumar, A., ... Rapoport, J. L. (1989). Cerebral Glucose Metabolism in Childhood-Onset Obsessive-Compulsive Disorder. Archives of General Psychiatry. https://doi.org/10.1001/archpsyc.1989.01810060038007

Szeszko, P. R., Christian, C., MacMaster, F., Lencz, T., Mirza, Y., Taormina, S. P., ... Rosenberg, D. R. (2008). Gray matter structural alterations in psychotropic drug-naive pediatric obsessive-compulsive disorder: An optimized voxel-based morphometry study. American Journal of Psychiatry, 165(10), 1299-1307. https://doi.org/10.1176/appi.ajp.2008.08010033

Tan, L., Fan, Q., You, C., Wang, J., Dong, Z., Wang, X., ... Jiang, K. (2013). Structural changes in the gray matter of unmedicated patients with obsessive-compulsive disorder: A voxel-based morphometric study. Neuroscience Bulletin, 29(5), 642-648. https://doi.org/10.1007/s12264-013$1370-7$

Tang, Wanjie, Huang, X., Li, B., Jiang, X., Li, F., Xu, J., ... Gong, Q. (2015). Structural Brain Abnormalities Correlate with Clinical Features in Patients with Drug-Naïve OCD: A DARTELenhanced Voxel-Based Morphometry Study. Elsevier B.V. https://doi.org/10.1016/j.bbr.2015.07.061 
Tang, Wanjie, Li, B., Huang, X., Jiang, X., Li, F., Wang, L., .. Yang, Y. (2013). Morphometric brain characterization of refractory obsessive-compulsive disorder: Diffeomorphic anatomic registration using exponentiated Lie algebra. Progress in Neuro-Psychopharmacology and Biological Psychiatry, 46, 126-131. https://doi.org/10.1016/j.pnpbp.2013.07.011

Tang, Wenxin, Zhu, Q., Gong, X., Zhu, C., Wang, Y., \& Chen, S. (2016). Cortico-striato-thalamo-cortical circuit abnormalities in obsessive-compulsive disorder: A voxel-based morphometric and fMRI study of the whole brain. Behavioural Brain Research, 313, 17-22. https://doi.org/10.1016/j.bbr.2016.07.004

Togao, O., Yoshiura, T., Nakao, T., Nabeyama, M., Sanematsu, H., Nakagawa, A., ... Honda, H. (2010). Regional gray and white matter volume abnormalities in obsessive-compulsive disorder: A voxelbased morphometry study. Psychiatry Research - Neuroimaging, 184(1), 29-37. https://doi.org/10.1016/j.pscychresns.2010.06.011

Valencia-Alfonso, C. E., Luigjes, J., Smolders, R., Cohen, M. X., Levar, N., Mazaheri, A., ... Denys, D. (2012). Effective deep brain stimulation in heroin addiction: A case report with complementary intracranial electroencephalogram. Biological Psychiatry. https://doi.org/10.1016/j.biopsych.2011.12.013

Valente, A. A., Miguel, E. C., Castro, C. C., Amaro, E., Duran, F. L. S., Buchpiguel, C. A., ... Busatto, G. F. (2005). Regional gray matter abnormalities in obsessive-compulsive disorder: A voxel-based morphometry study. Biological Psychiatry. https://doi.org/10.1016/j.biopsych.2005.04.021

Van Den Heuvel, O. A., Remijnse, P. L., Mataix-Cols, D., Vrenken, H., Groenewegen, H. J., Uylings, H. B. M., ... Veltman, D. J. (2009). The major symptom dimensions of obsessive-compulsive disorder are mediated by partially distinct neural systems. Brain. https://doi.org/10.1093/brain/awn267

van Holst, R. J., de Ruiter, M. B., van den Brink, W., Veltman, D. J., \& Goudriaan, A. E. (2012). A voxel-based morphometry study comparing problem gamblers, alcohol abusers, and healthy controls. Drug and Alcohol Dependence, 124(1-2), 142-148. https://doi.org/10.1016/j.drugalcdep.2011.12.025

Vaquero, L., Cámara, E., Sampedro, F., Pérez de los Cobos, J., Batlle, F., Fabregas, J. M., ... Riba, J. (2017). Cocaine addiction is associated with abnormal prefrontal function, increased striatal connectivity and sensitivity to monetary incentives, and decreased connectivity outside the human reward circuit. Addiction Biology, 22(3), 844-856. https://doi.org/10.1111/adb.12356

Vollstädt-Klein, S., Wichert, S., Rabinstein, J., Bühler, M., Klein, O., Ende, G., .. Mann, K. (2010). 
Initial, habitual and compulsive alcohol use is characterized by a shift of cue processing from ventral to dorsal striatum. Addiction, 105(10), 1741-1749. https://doi.org/10.1111/j.13600443.2010.03022.x

Wang, J., Fan, Y., Dong, Y., Ma, M., Ma, Y., Dong, Y., ... Cui, C. (2016). Alterations in brain structure and functional connectivity in alcohol dependent patients and possible association with impulsivity. PLoS ONE, 11(8), 1-19. https://doi.org/10.1371/journal.pone.0161956

Wang, K., Yang, J., Zhang, S., Wei, D., Hao, X., Tu, S., \& Qiu, J. (2014). The neural mechanisms underlying the acute effect of cigarette smoking on chronic smokers. PLoS ONE, 9(7), 1-8. https://doi.org/10.1371/journal.pone.0102828

Wetherill, R. R., Jagannathan, K., Hager, N., Childress, A. R., Rao, H., \& Franklin, T. R. (2015). Cannabis, cigarettes, and their co-occurring use: Disentangling differences in gray matter volume. International Journal of Neuropsychopharmacology. https://doi.org/10.1093/ijnp/pyv061

Wiers, C. E., Gawron, C. K., Gröpper, S., Spengler, S., Stuke, H., Lindenmeyer, J., ... Bermpohl, F. (2015). Decreased gray matter volume in inferior frontal gyrus is related to stop-signal task performance in alcohol-dependent patients. Psychiatry Research - Neuroimaging, 233(2), 125-130. https://doi.org/10.1016/j.pscychresns.2015.05.006

Xiao, P. R., Dai, Z. Y., Zhong, J. G., Zhu, Y. L., Shi, H. C., \& Pan, P. L. (2015). Regional gray matter deficits in alcohol dependence: A meta-analysis of voxel-based morphometry studies. Drug and Alcohol Dependence. https://doi.org/10.1016/j.drugalcdep.2015.05.030

Yang, X., Tian, F., Zhang, H., Zeng, J., Chen, T., Wang, S., ... Gong, Q. (2016). Cortical and subcortical gray matter shrinkage in alcohol-use disorders: A voxel-based meta-analysis. Neuroscience and Biobehavioral Reviews, 66(37), 92-103. https://doi.org/10.1016/j.neubiorev.2016.03.034

Yip, S. W., Worhunsky, P. D., Xu, J., Morie, K. P., Constable, R. T., Malison, R. T., ... Potenza, M. N. (2018). Gray-matter relationships to diagnostic and transdiagnostic features of drug and behavioral addictions. Addiction Biology, 23(1), 394-402. https://doi.org/10.1111/adb.12492

Yokoyama, N., Sasaki, H., Mori, Y., Ono, M., Tsurumi, K., Kawada, R., ... Takahashi, H. (2018). Additive Effect of Cigarette Smoking on Gray Matter Abnormalities in Schizophrenia. Schizophrenia Bulletin, 44(3), 535-541. https://doi.org/10.1093/schbul/sbx092

Yücel, M., Harrison, B. J., Wood, S. J., Fornito, A., Wellard, R. M., Pujol, J., ... Pantelis, C. (2007). Functional and biochemical alterations of the medial frontal cortex in obsessive-compulsive 
disorder. Archives of General Psychiatry. https://doi.org/10.1001/archpsyc.64.8.946

Yun, J. Y., Jang, J. H., Jung, W. H., Shin, N. Y., Kim, S. N., Hwang, J. Y., \& Kwon, J. S. (2017).

Executive dysfunction in obsessive-compulsive disorder and anterior cingulate-based resting state functional connectivity. Psychiatry Investigation. https://doi.org/10.4306/pi.2017.14.3.333

Zang, Z. X., Yan, C. G., Dong, Z. Y., Huang, J., \& Zang, Y. F. (2012). Granger causality analysis implementation on MATLAB: A graphic user interface toolkit for fMRI data processing. Journal of Neuroscience Methods. https://doi.org/10.1016/j.jneumeth.2011.10.006

Zhou, X., Zimmermann, K., Xin, F., Zhao, W., Derckx, R. T., Sassmannshausen, A., ... Becker, B. (2019). Cue Reactivity in the Ventral Striatum Characterizes Heavy Cannabis Use, Whereas Reactivity in the Dorsal Striatum Mediates Dependent Use. Biological Psychiatry: Cognitive Neuroscience and Neuroimaging, 4(8), 751-762. https://doi.org/10.1016/j.bpsc.2019.04.006

Zilverstand, A., Huang, A. S., Alia-Klein, N., \& Goldstein, R. Z. (2018). Neuroimaging Impaired Response Inhibition and Salience Attribution in Human Drug Addiction: A Systematic Review. Neuron. https://doi.org/10.1016/j.neuron.2018.03.048

Zubieta, J. K., Lombardi, U., Minoshima, S., Guthrie, S., Ni, L. S., Ohl, L. E., ... Domino, E. F. (2001). Regional cerebral blood flow effects of nicotine in overnight abstinent smokers. Biological Psychiatry, 49(11), 906-913. https://doi.org/10.1016/S0006-3223(00)01070-2 